\title{
TES ammonia retrieval strategy and global observations of the spatial and seasonal variability of ammonia
}

\author{
M. W. Shephard ${ }^{1, *}$, K. E. Cady-Pereira ${ }^{2}$, M. Luo ${ }^{3}$, D. K. Henze ${ }^{4}$, R. W. Pinder ${ }^{5}$, J. T. Walker ${ }^{5}$, C. P. Rinsland ${ }^{* *}, \dagger$, \\ J. O. Bash ${ }^{5}$, L. Zhu ${ }^{4}$, V. H. Payne ${ }^{2}$, and L. Clarisse ${ }^{6}$ \\ ${ }^{1}$ Environment Canada, Downsview, Ontario, Canada \\ ${ }^{2}$ Atmospheric and Environmental Research, Inc., Lexington, Massachusetts, USA \\ ${ }^{3}$ Jet Propulsion Laboratory, California Institute of Technology Pasadena, CA, USA \\ ${ }^{4}$ University of Colorado, Boulder, Colorado, USA \\ ${ }^{5}$ US Environmental Protection Agency, Research Triangle Park, North Carolina, USA \\ ${ }^{6}$ Spectroscopie de l'Atmosphere, Service de Chimie Quantique et Photophysique, Universite Libre de Bruxelles (U.L.B.), \\ Brussels, Belguim \\ * presently at: Atmospheric and Climate Applications (ACApps), Inc., East Gwillimbury, Ontario, Canada \\ ${ }^{* * *}$ formerly at: NASA Langley Research Center, Hampton, VA, USA \\ $\dagger$ deceased
}

Received: 8 March 2011 - Published in Atmos. Chem. Phys. Discuss.: 26 May 2011

Revised: 6 October 2011 - Accepted: 7 October 2011 - Published: 31 October 2011

\begin{abstract}
Presently only limited sets of tropospheric ammonia $\left(\mathrm{NH}_{3}\right)$ measurements in the Earth's atmosphere have been reported from satellite and surface station measurements, despite the well-documented negative impact of $\mathrm{NH}_{3}$ on the environment and human health. Presented here is a detailed description of the satellite retrieval strategy and analysis for the Tropospheric Emission Spectrometer (TES) using simulations and measurements. These results show that: (i) the level of detectability for a representative boundary layer TES $\mathrm{NH}_{3}$ mixing ratio value is $\sim 0.4 \mathrm{ppbv}$, which typically corresponds to a profile that contains a maximum level value of $\sim 1$ ppbv; (ii) TES $\mathrm{NH}_{3}$ retrievals generally provide at most one degree of freedom for signal (DOFS), with peak sensitivity between 700 and 900 mbar; (iii) TES $\mathrm{NH}_{3}$ retrievals show significant spatial and seasonal variability of $\mathrm{NH}_{3}$ globally; (iv) initial comparisons of TES observations with GEOS-CHEM estimates show TES values being higher overall. Important differences and similarities between modeled and observed seasonal and spatial trends are noted, with discrepancies indicating areas where the timing and magnitude of modeled $\mathrm{NH}_{3}$ emissions from agricultural sources, and to lesser extent biomass burning sources, need further study.
\end{abstract}

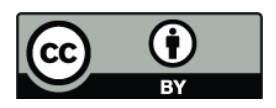

Correspondence to: M. W. Shephard (mark.shephard@acappsinc.com)

\section{Introduction}

Global high-spectral resolution nadir measurements from the Tropospheric Emissions Spectrometer (TES) on NASA's Aura platform enable the simultaneous retrieval of a number of tropospheric pollutants and minor trace gases in addition to standard operationally retrieved products (temperature, water vapor, ozone, carbon monoxide, and methane). Ammonia $\left(\mathrm{NH}_{3}\right)$ is one of the additional species that can be retrieved in conjunction with the TES standard products and is important for local, regional, and global tropospheric chemistry studies. $\mathrm{NH}_{3}$ contributes significantly to several well-known environmental problems; excess deposition in terrestrial ecosystems can lead to soil acidification and loss of plant diversity (e.g. Carfrae et al., 2004); in coastal ecosystems, it can cause eutrophication, algal blooms, and loss of fish and shellfish (e.g. Paerl et al., 2002). In the atmosphere $\mathrm{NH}_{3}$ can combine with sulfates and nitric acid to form ammonium nitrate and ammonium sulfate, which constitute a substantial fraction of fine particulate matter $\left(\mathrm{PM}_{2.5}\right)$ (e.g. Seinfeld and Pandis, 1988). These particles are statistically associated with health impacts (e.g. Pope et al., 2000) and contribute to atmospheric radiative forcing by the atmosphere (e.g. Charlson et al., 1991), while also impacting visibility. Nevertheless the knowledge of the magnitude and seasonal/spatial variability of the $\mathrm{NH}_{3}$ emissions is severely limited.

Published by Copernicus Publications on behalf of the European Geosciences Union. 
The greatest uncertainty in atmospheric transport of reactive nitrogen is in the rates of $\mathrm{NH}_{3}$ emission from all sources, at all scales (Galloway et al., 2008). In situ $\mathrm{NH}_{3}$ measurements are challenging and not available in many regions. Limiting factors in improving the emission inventory are infrequent and sparse in situ observations, and the reliance of previous inversion methods on using a limited number of available condensed-phase measurements (Gilliland et al., 2006; Henze et al., 2009). Satellite observations of tropospheric $\mathrm{NH}_{3}$ are therefore highly desirable (Beer et al., 2008), especially given the projections that free $\mathrm{NH}_{3}$ will increase with time, both for the eastern US (Pinder et al., 2008) and for agricultural regions over the entire globe, as the use of fertilizer continues to climb (Erisman et al., 2008).

First satellite observations of boundary layer tropospheric $\mathrm{NH}_{3}$ were reported by Beer et al. (2008) using TES-Aura nadir infrared FTS spectra. That study presented preliminary TES retrievals over a limited range of conditions. Similar to TES, the Infrared Atmospheric Sounder Interferometer (IASI) instrument also retrieves $\mathrm{NH}_{3}$ in nadir viewing mode using the thermal infrared spectral region. The excellent spatial coverage of the IASI instrument, coupled with a very simple and fast retrieval based on the conversion of brightness temperature differences into total column measurements, has provided a global picture of the distribution of $\mathrm{NH}_{3}$ (Clarisse et al., 2009). Clarisse et al. (2010) used a more refined algorithm to provide greater insight into the remote sensing of tropospheric $\mathrm{NH}_{3}$ and introduced important sensitivity issues (e.g. the impact of the thermal contrast on the boundary layer retrievals of $\mathrm{NH}_{3}$ ). Upper tropospheric limb emission measurements of $\mathrm{NH}_{3}$ have also been reported from MIPAS (Michelson Interferometer for Passive Atmospheric Sounding) limb-sounding measurements (Burgess et al., 2006).

TES has less dense spatial coverage than scanning satellites (e.g. IASI, AIRS), but has a higher spectral resolution of $0.06 \mathrm{~cm}^{-1}$ (compared to more typical scanning infrared satellite sensors with $\left.0.5-1.0 \mathrm{~cm}^{-1}\right)$. The combination of the higher spectral resolution and good signal-to-noise (SNR) of the TES instrument in the $\mathrm{NH}_{3}$ region (Shephard et al., 2008) provides increased sensitivity to $\mathrm{NH}_{3}$ mixing ratios near the surface from satellite observations. In addition, TES is in a sun-synchronous orbit that has both a daytime ascending orbit with a local overpass time of 13:30 mean solar time, providing favorable conditions for high thermal contrast and thus increased sensitivity to boundary layer $\mathrm{NH}_{3}$ (Clarisse et al., 2010), and a nighttime descending orbit with a corresponding 01:30 local overpass time. The high spectral resolution also allows for selection of spectral regions (microwindows) that reduce the impact of interfering species, and consequently systematic errors in the retrievals. The smaller footprint of TES $(5 \times 8 \mathrm{~km})$ also allows for the potential to detect localized $\mathrm{NH}_{3}$ sources. These TES sensor characteristics and a sophisticated global retrieval algorithm provide the capability to obtain a more detailed estimate of $\mathrm{NH}_{3}$ not previously available over most of the globe.

Presented here are results that expand upon the initial TES $\mathrm{NH}_{3}$ observations provided by Beer et al. (2008) and include: (i) detailed description of the TES $\mathrm{NH}_{3}$ retrieval strategy including error characterization; (ii) estimation of the TES level of detectability of $\mathrm{NH}_{3}$ under various conditions based directly on the SNR; (iii) evaluation of the TES $\mathrm{NH}_{3}$ retrieval performance using simulations; (iv) TES $\mathrm{NH}_{3}$ observation examples showing the spatial and seasonal variability of $\mathrm{NH}_{3}$ globally; (v) initial comparison results of TES observations with GEOS-Chem model output globally and over twelve distinct regions.

\section{Retrieval strategy and sensitivity studies}

\subsection{Retrieval strategy}

\subsubsection{Retrieval methodology}

The TES $\mathrm{NH}_{3}$ retrieval is based on an optimal estimation approach that minimizes the difference between the observed spectral radiances and a nonlinear radiative transfer model driven by the atmospheric state, subject to the constraint that the estimated state must be consistent with an a priori probability distribution for that state (Bowman et al., 2006). If the estimated (retrieved) state is close to the actual state, then the estimated state can be expressed in terms of the actual state through the linear retrieval (Rodgers, 2000):

$\hat{\boldsymbol{x}}=\boldsymbol{x}_{\mathrm{a}}+\mathbf{A}\left(\boldsymbol{x}-\boldsymbol{x}_{\mathrm{a}}\right)+\mathbf{G} \boldsymbol{n}+\mathbf{G K}_{\mathrm{b}}\left(\boldsymbol{b}-\boldsymbol{b}_{\mathrm{a}}\right)$,

where, $\hat{\boldsymbol{x}}, \boldsymbol{x}_{\mathrm{a}}$, and $\boldsymbol{x}$ are the retrieved, a priori, and the "true" state vectors respectively. For TES trace gas retrievals, these are expressed as the natural logarithm of volume mixing ratio (VMR). $\mathbf{G}$ is the gain matrix, which maps from measurement (spectral radiance) space into retrieval space. The vector $\boldsymbol{n}$ represents the noise on the spectral radiances. The vector $\boldsymbol{b}$ represents the true state for those parameters that also affect the modeled radiance (e.g. concentrations of interfering gases, calibration, etc.). $\boldsymbol{b}_{\mathrm{a}}$ holds the corresponding a priori values, and the Jacobian, $\mathbf{K}_{\mathbf{b}}=\partial \mathbf{L} / \partial \boldsymbol{b}$, describes the dependency of the forward model radiance, $\mathbf{L}$, on the vector $\boldsymbol{b}$. Further details on the Line-By-Line Radiative Transfer Model (LBLRTM) and the fast forward model (OSS-TES) used for the forward model calculations can be found in Clough et al. (2005), Moncet et al. (2008) and Shephard et al. (2009).

$\mathbf{A}=\frac{\partial \hat{\boldsymbol{x}}}{\partial \boldsymbol{x}}=\left(\mathbf{K}^{T} \mathbf{S}_{n} \mathbf{K}+\Lambda\right)^{-1} \mathbf{K}^{T} \mathbf{S}_{n}^{-1} \mathbf{K}=\mathbf{G K}$.

The averaging kernel, $\mathbf{A}$, describes the sensitivity of the retrieval to the true state: $\mathbf{K}$ describes the sensitivity of the forward model radiances to the state vector $(\mathbf{K}=\partial \mathbf{L} / \partial \boldsymbol{x}) . \mathbf{S}_{n}$ is the noise covariance matrix, representing the noise in the measured radiances, and $\boldsymbol{\Lambda}$ is the constraint matrix for the retrieval. 
For profile retrievals, the rows of $\mathbf{A}$ are functions with some finite width that give a measure of the vertical resolution of the retrieval. The sum of each row of $\mathbf{A}$ represents an estimate of the fraction of retrieval information that comes from the measurement rather than the a priori (Rodgers, 2000) at the corresponding altitude, provided the retrieval is relatively linear. The trace of the averaging kernel matrix gives the number of degrees of freedom for signal (DOFS) from the retrieval.

The relatively low spectral contribution of the mostly boundary layer $\mathrm{NH}_{3}$ infrared nadir signal $(\sim 1 \mathrm{~K}$ brightness temperature for a polluted profile) compared with the background atmospheric state, and the lack of site-specific $\mathrm{NH}_{3}$ a priori information, present additional challenges to the retrieval of $\mathrm{NH}_{3}$ compared with more traditional retrieved species (e.g. ozone, water vapor). Since tropospheric $\mathrm{NH}_{3}$ retrievals from nadir mid-tropospheric infrared spectra have not been routinely performed, specific details into the retrieval approach are provided. The $\mathrm{NH}_{3}$ retrievals are carried out after the retrievals of temperature, water vapor, ozone, methane, carbon dioxide, clouds, and surface temperature and emissivity (using V004 TES products). For this initial study we only performed retrievals where the TES retrieved cloud optical depths were $\leq 1.0$. Adjustments to the surface emissivity and temperature are carried out simultaneously with the $\mathrm{NH}_{3}$ retrieval.

\subsubsection{Retrieval error analysis}

An advantage of the optimal estimation retrieval approach is that an error estimate can be computed in a straight-forward manner utilizing retrieval input parameters. The total error on the retrieved profile can be expressed as the sum of the representation (smoothing) error, the cross-state error, which accounts for errors due to other parameters in the joint retrieval (i.e. temperature and ozone), and the measurement error (due to instrument random noise and the systematic errors (Worden et al., 2004). In this initial analysis the total error estimates (e.g. Fig. 8) do not include any contribution from cross-state or systematic errors. One of the main potential systematic errors that was considered is the errors in the spectroscopic parameters. The spectroscopic line in HITRAN 2004 (Rothman et al., 2005) originated from the HITRAN 2000 compilation (Rothman et al., 2003). Those parameters were described in the paper by Kleiner et al. (2003). Intensities for ${ }^{14} \mathrm{NH}_{3}$ near the $10 \mu \mathrm{m}$ (the only isotopologue of significance for the present work) were derived from laboratory measurements at the US National Solar Observatory. As described in that summary, the best-fit derived from a fit to those measurements has a standard deviation of $<1 \%$. Air-pressure-broadening coefficients were calculated from a polynomial best-fit to experimental measurements reported in several studies. Based on both results, we have estimated the total uncertainty due to potential bias in the assumed
Table 1. Microwindows for TES $\mathrm{NH}_{3}$ retrievals.

\begin{tabular}{lllll}
\hline Index & Filter & $V_{1}\left(\mathrm{~cm}^{-1}\right)$ & $V_{2}\left(\mathrm{~cm}^{-1}\right)$ & $\begin{array}{l}\text { Retrieved } \\
\text { Parameter }\end{array}$ \\
\hline 1 & 1B2 & 949.82 & 950.90 & emiss \\
2 & 1B2 & 956.50 & 957.50 & emiss \\
3 & 1B2 & 962.06 & 962.42 & $\mathrm{NH}_{3}$ \\
4 & 1B2 & 963.38 & 964.64 & $\mathrm{NH}_{3}$ \\
5 & 1B2 & 964.94 & 965.66 & $\mathrm{NH}_{3}$ \\
6 & 1B2 & 966.38 & 966.62 & $\mathrm{NH}_{3}$ \\
7 & 1B2 & 967.10 & 967.52 & $\mathrm{NH}_{3}$ \\
8 & 1B2 & 967.88 & 968.18 & $\mathrm{NH}_{3}$ \\
9 & 1B2 & 968.24 & 968.8 & Emiss \& $\mathrm{NH}_{3}$ bkgd \\
10 & 1B2 & 972.20 & 973.0 & emiss \\
\hline
\end{tabular}

$V_{1}$ and $V_{2}$ are the beginning and ending wavenumbers of the microwindow. The spectral resolution of the microwindow is $0.06 \mathrm{~cm}^{-1}$.

spectroscopic parameters as $<1 \%$. Since this is well below other sources of retrieval error it is ignored in this study.

\subsubsection{TES $\mathrm{NH}_{3}$ microwindows}

Rather than using an entire TES band, the TES retrieval algorithms define spectral microwindows for retrieving each parameter in order to reduce the impact of interfering species and increase computational speed. For the $\mathrm{NH}_{3}$ retrievals we have selected microwindows for the background window calculation, the surface temperature and emissivity. Figure 1 shows a simulated sensitivity analysis depicting the $\mathrm{NH}_{3}$ microwindows and interfering species. Table 1 contains the microwindows used in the $\mathrm{NH}_{3}$ retrievals. The microwindows were carefully chosen to minimize signal from interfering species, (e.g. water vapor) and maximize the surface and $\mathrm{NH}_{3}$ signal. Also note that the spectral region for these TES ammonia retrievals is not previously used by any other TES retrieval, which greatly reduces the impact of other retrievals on the $\mathrm{NH}_{3}$ retrievals.

\subsubsection{A priori vector and constraints}

The a priori profiles for TES $\mathrm{NH}_{3}$ retrievals are derived from the GEOS-Chem model simulations of 2005 global distributions of $\mathrm{NH}_{3}$. GEOS-Chem is a chemical transport model driven using assimilated meteorology from the Goddard Earth Observing System (GEOS) of the NASA Global Modeling and Assimilation Office (GMAO). The GEOSChem $\mathrm{NH}_{3}$ emissions for anthropogenic and natural sources are originally based on data from the 1990 GEIA inventory of Bouwman et al. (1997), with additional contributions owing to biomass burning and biofuel use from inventories by Duncan et al. (2003) and Yevich and Logan (2003). Monthly variability is calculated according to an exponential temperature scaling (Adams et al., 1999), with additional top-down constraints provided from Gilliland et al. (2003). Figure 2 

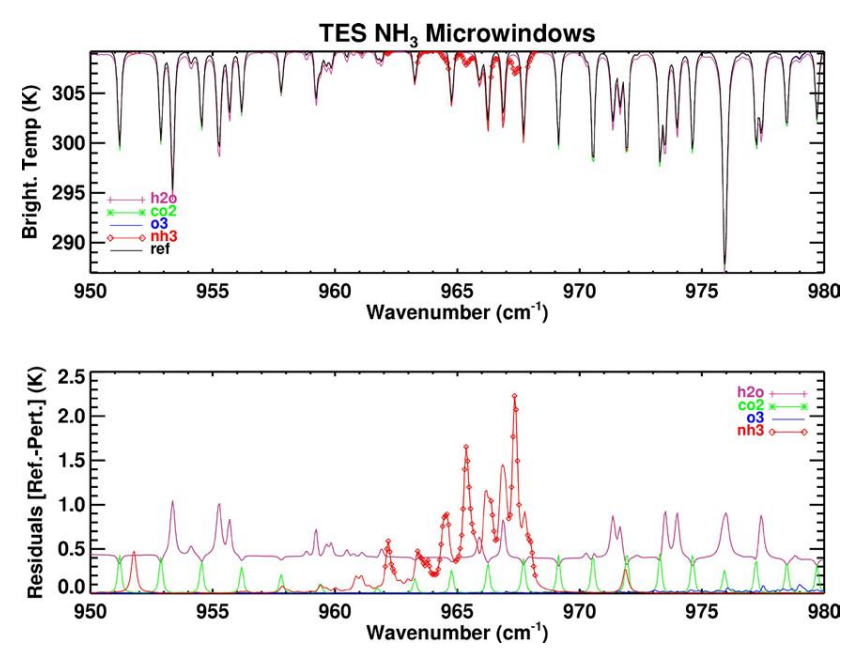

Fig. 1. Plot of the TES spectral microwindow selection for $\mathrm{NH}_{3}$ retrievals. The top panel is the model (LBLRTM) simulated TES observation for a reference atmosphere (plotted in black). Overplotted in color are various simulated model calculations the reference atmospheric profile has been additionally perturbed separately by $10 \% \mathrm{H}_{2} \mathrm{O}, 10 \% \mathrm{CO}_{2}, 10 \% \mathrm{O}_{3}$, and the $\mathrm{NH}_{3}$ increased to a polluted profile. The bottom panel shows the residual (reference - perturbation) TOA brightness temperatures. The diamonds represent spectral points in the $\mathrm{NH}_{3}$ microwindows.

presents the monthly GEOS-Chem mean $\mathrm{NH}_{3}$ volume mixing ratios at the surface. The enhanced surface $\mathrm{NH}_{3}$ correlates with the intensities of the seasonally varying emission sources in the model. Due to its short lifetime, $\mathrm{NH}_{3}$ exhibits strong spatial and temporal variability, and a wide range of values (over three orders of magnitude at the surface); thus more than one a priori profile was created for the retrieval to take into account the non-linear nature of the retrieval problem. To build the TES $\mathrm{NH}_{3}$ a priori profiles we generated three categories of $\mathrm{NH}_{3}$ profiles, "polluted", "moderately polluted", and "unpolluted", starting from a GEOS-Chem model run on a $2^{\circ}$ latitude by $2.5^{\circ}$ longitude grid for 2005 . Figure 3 shows the individual profiles and the averaged profiles for each category. The "polluted" a priori profile is the average of all profiles with surface $\mathrm{NH}_{3} \mathrm{VMR} \geq 5 \mathrm{ppbv}$. The "moderately polluted" a priori profile is the average of all profiles with $1 \mathrm{ppbv} \leq \mathrm{NH}_{3}<5 \mathrm{ppbv}$ at the surface or $\mathrm{NH}_{3}$ $<1 \mathrm{ppbv}$ at the surface, but greater than $1 \mathrm{ppbv}$ between the surface and $500 \mathrm{hPa}$; this profile type seeks to represent those cases in which the local emissions are less than the transport into the region. Finally, the "unpolluted" a priori profile is the average of all profiles with $\mathrm{NH}_{3}<1 \mathrm{ppbv}$ between the surface and $800 \mathrm{hPa}$. Note that unlike other species commonly retrieved from infrared nadir measurements, $\mathrm{NH}_{3}$ is heavily concentrated in the boundary layer, especially in polluted environments. The variability of each of the three a priori profiles is also derived from the GEOS-Chem model data. Figure 4 shows the square roots of the diagonals of the covariance matrices, which are the basis for generating the constraint matrix used in the retrievals. The constraints were modified to reflect the sensitivity of the TES (i.e. where there is very little $\mathrm{NH}_{3}$ and no TES sensitivity, e.g. above $400 \mathrm{hPa}$, the retrieval is constrained back to the a priori). The off-diagonals of the constraint matrix were generated with a $1-\mathrm{km}$ correlation length.

The $\mathrm{NH}_{3}$ concentrations are highly variable in time and space and not well known, especially outside the US and Europe. Therefore, for a given TES target scene there are usually no a priori site specific observations or assimilated model output. To provide additional insight into the selection of one of the three possible three GEOS-Chem profiles used for the $\mathrm{NH}_{3}$ initial guess and a priori profiles it is beneficial to examine the strength of the $\mathrm{NH}_{3}$ signal in the measured radiance.

The strength of the TES $\mathrm{NH}_{3}$ infrared spectral signature can be represented as a signal to noise ratio (SNR), which is a function of a number of parameters such as the $\mathrm{NH}_{3}$ concentration, temperature profile, clouds, and surface thermal contrast. In order to examine the sensitivity of the SNR to these parameters, we obtained retrieved atmospheric profiles of temperature, water vapor and ozone, plus retrieved surface temperature and emissivity, from two TES Global Series (GS), one from January and one from July, consisting of 180 measurements over land between $60^{\circ} \mathrm{N}$ and $60^{\circ} \mathrm{S}$. To each profile three different simulated $\mathrm{NH}_{3}$ profiles representing unpolluted, moderately polluted, and polluted conditions were added, which built a set of 540 cases. To create a range of simulated $\mathrm{NH}_{3}$ profiles, we took each of the a priori profiles and applied a scaling factor determined from a normal random number generator. This set was then used as input for the TES-OSS forward radiative transfer model in order to generate simulated TES spectra. From each spectrum we calculated a SNR value, defined as the difference between the background brightness temperature (BT) and the BT in the $\mathrm{NH}_{3}$ spectral region, and divided by the expected TES noise (see Appendix A for SNR calculation details).

The results of this simulated sensitivity analysis are in Fig. 5, where the SNR is plotted as a function of the thermal contrast. The points corresponding to each profile type fall roughly in three regions on the plot, suggesting that these two parameters can be used to estimate the $\mathrm{NH}_{3}$ profile type corresponding to the SNR and thermal contrast. The selection of the profile type is correctly estimated more often when the absolute value of the SNR is greater than 1.0 and the thermal contrast is greater than $5.0 \mathrm{~K}$ or less than $-3.0 \mathrm{~K}$. If these thresholds are not met then the default unpolluted a priori and moderate initial guess profiles are used in the retrieval. The scatter for each type can be attributed to other factors important in the SNR determination not considered here, such the structure of the temperature profile, the amount of water vapor and the location of the maximum $\mathrm{NH}_{3}$ concentration. This plot was used to build the a priori selection criteria. 

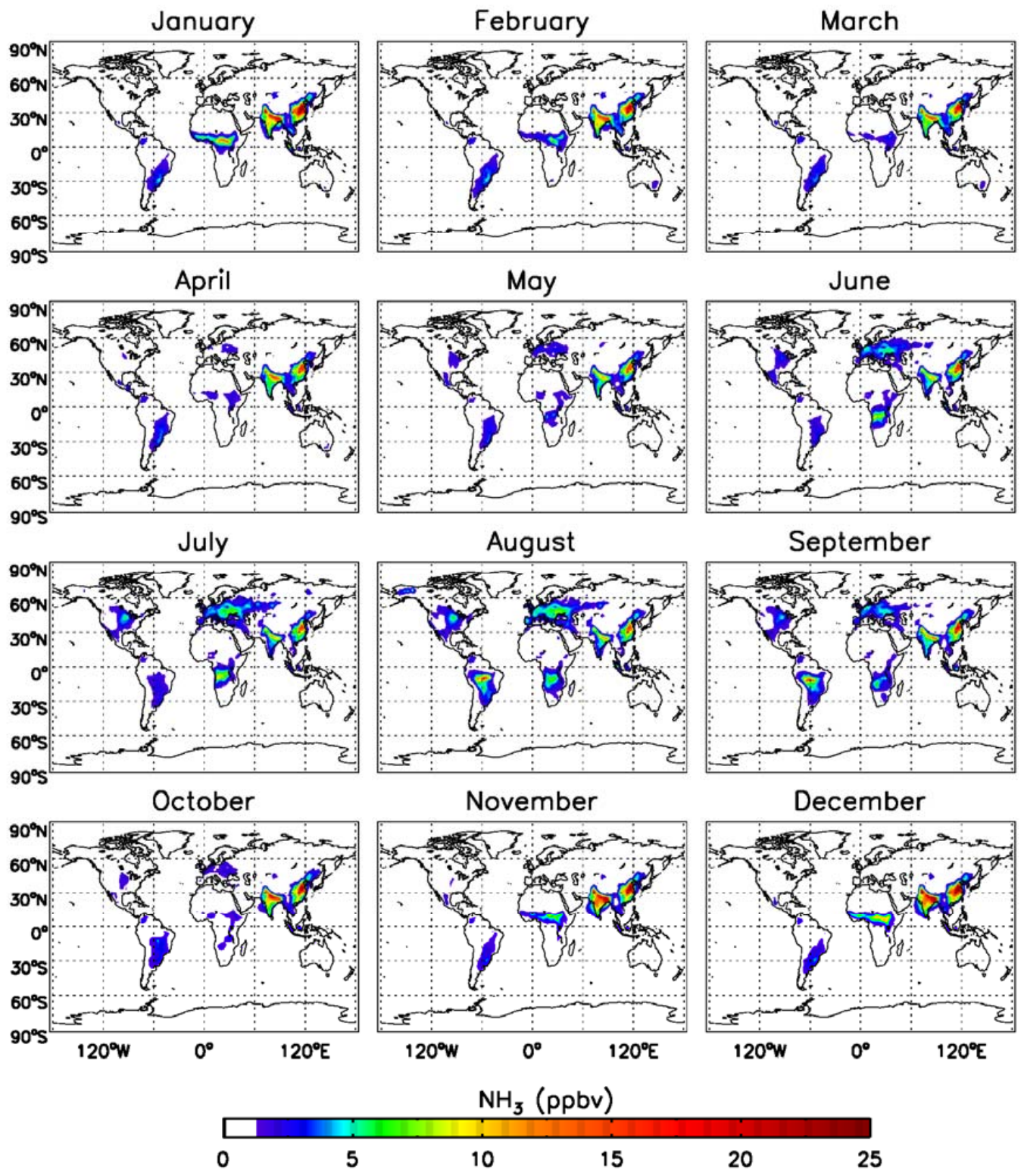

Fig. 2. GEOS-Chem monthly mean surface $\mathrm{NH}_{3}$ mixing ratio amounts.

\subsection{Sensitivity studies}

\subsubsection{Level of detectability}

The minimum requirement for TES to detect $\mathrm{NH}_{3}$ is that the TES signal in the $\mathrm{NH}_{3}$ spectral region be greater than the expected TES noise in this region. Using the simulation set discussed in Sect. 2.1.4, we estimated this signal as the BT difference between runs with and without $\mathrm{NH}_{3}$, divided by the TES noise. Note that this value, which can also be termed an SNR, is different from the SNR defined in Sect. 2.1.4, since here it is calculated from the difference between two spectra, rather than from the difference between two spectral regions. In effect, the SNR in Sect. 2.1.4 is an estimate of the true SNR calculated here.

Each SNR was plotted in the thermal contrast/ $/ \mathrm{NH}_{3}$ plane (Fig. 6). The filled circles represent cases where the $\mathrm{SNR} \geq 1$, and empty circles otherwise. The circles are colored according to the pollution level of the $\mathrm{NH}_{3}$ profile; the percentage of detectable profiles of each type is also shown on the plot. Several conclusions can be drawn from this figure: 

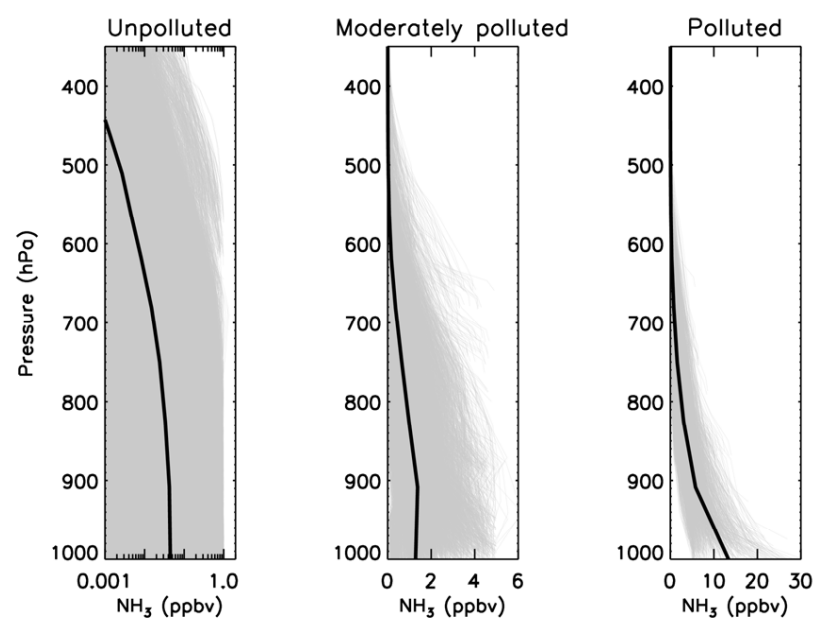

Fig. 3. Three sets of atmospheric $\mathrm{NH}_{3}$ monthly mean profiles (gray) from GEOS-Chem 2005 global model simulations. The mean profile for each set is shown in black. These three mean $\mathrm{NH}_{3}$ profiles constitute the TES $\mathrm{NH}_{3}$ retrieval a priori profiles.

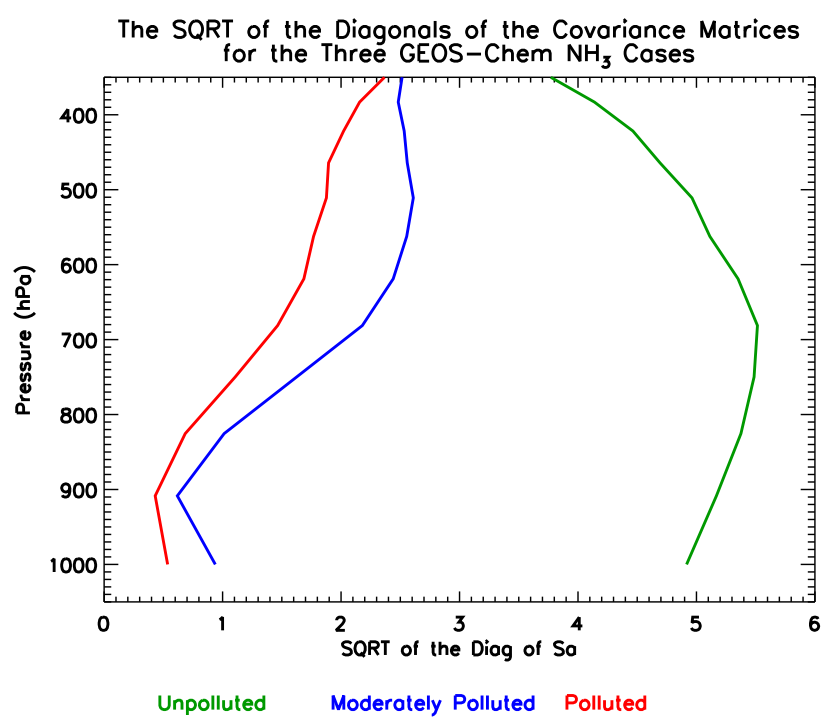

Fig. 4. The square root (SQRT) of the diagonals of the three covariance matrices derived from the GEOS-Chem $\mathrm{NH}_{3}$ global monthly mean profiles (unpolluted, moderately polluted, and polluted), in $\ln \mathrm{VMR}$, plotted as functions of pressure.

- polluted profiles are usually detectable $(85 \%)$;

- unpolluted profiles rarely are detectable;

- thermal contrast increases detectability;

- the TES minimum level of detectability is for a profile that contains a peak level value of $\sim 1$ ppbv.

The distribution of points with SNR greater than 1 suggests that the minimum detectability level will be influenced

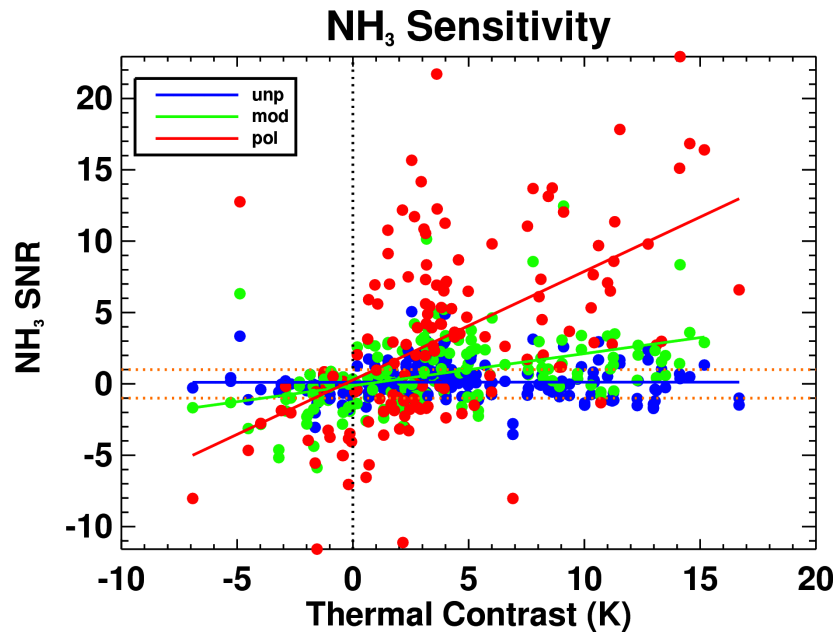

Fig. 5. Scatter plot of SNR over the TES $\mathrm{NH}_{3}$ band versus the thermal contrast (surface temperature - air temperature at the bottom of the profile) for unpolluted (blue), moderately polluted (green), and polluted (red) $\mathrm{NH}_{3}$ profiles. The straight lines are linear fits to the results for each profile type. The two horizontal dashes lines (yellow) correspond to the SNR of \pm 1 .

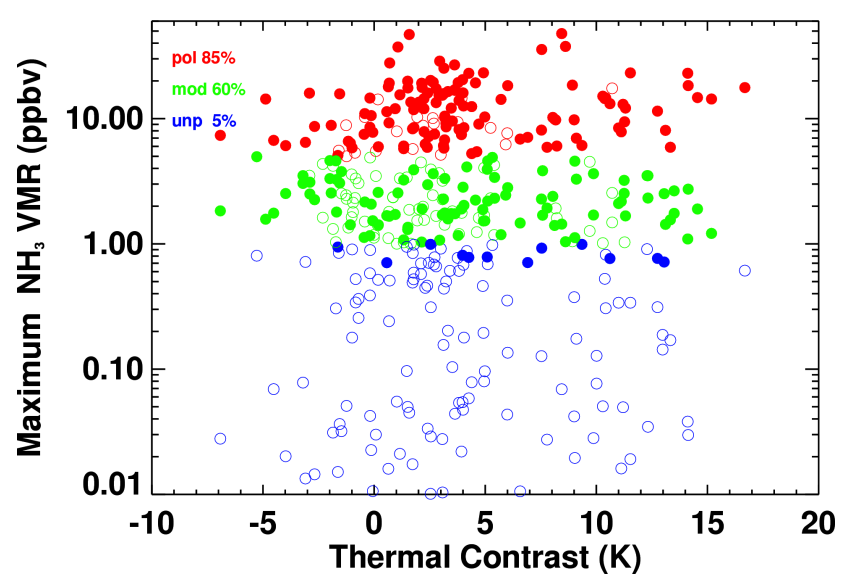

Fig. 6. Scatter plot of the maximum $\mathrm{NH}_{3}$ VMR in each profile as a function of thermal contrast for the same simulated data set used in Fig. 5. The filled circles indicate spectra with $\mathrm{NH}_{3} \mathrm{SNR} \geq 1$ whereas the open circles correspond to $\mathrm{NH}_{3} \mathrm{SNR}<1$. The colors correspond to unpolluted (blue), moderately polluted (green), and polluted (red) $\mathrm{NH}_{3}$ profiles. Also provided are the percentage of cases for each polluted condition that meet the SNR $>1$ criteria.

by a number of factors such as the altitude of the peak $\mathrm{NH}_{3}$ concentration and the thermal structure of the atmosphere. For example, if the thermal contrast is low (in general less than $5 \mathrm{~K}$ ) it is difficult to reach the minimum detectability level of a profile with a peak value of $1 \mathrm{ppbv}$. 


\subsubsection{Cloud sensitivity study}

TES performs a cloud retrieval that accounts for the impacts of clouds on the passive infrared retrievals (Eldering et al., 2008; Kulawik et al., 2006). Since the $\mathrm{NH}_{3}$ signal is relatively small compared to the overall background infrared signal, a simple cloud sensitivity study was performed to determine the effect of clouds on the performance of $\mathrm{NH}_{3}$ retrievals. The sensitivity of the $\mathrm{NH}_{3}$ retrieval information content to cloud was tested by running the forward model with a polluted $\mathrm{NH}_{3}$ profile and clouds of varying optical depth and height. The $\mathrm{NH}_{3}$ averaging kernels were also computed for each case to provide the information content (DOFS). As expected, as the cloud optical depth increases (Fig. 7) there is less measurement information available to the retrieval and the DOFS decrease; the $\mathrm{NH}_{3}$ retrieval information content increases slightly with decreasing cloud altitudes, especially from $\sim 700 \mathrm{hPa}$ towards to the surface, where the highest concentration of $\mathrm{NH}_{3}$ is located. As an illustration, in this typical $\mathrm{NH}_{3}$ polluted retrieval the DOFS would go from 0.90 in clear sky conditions to $\sim 0.65$ when a cloud with an optical depth $=1$ is present. It is important to note that this sensitivity study shows the impact of the cloud on $\mathrm{NH}_{3}$ retrievals if no cloud retrieval were performed. Since TES retrievals account for the radiative effects of clouds by retrieving an effective cloud optical depth and cloud height the impact of the thin clouds on the $\mathrm{NH}_{3}$ retrievals is mitigated; however, the information content below the clouds is reduced. The simulations show that for a polluted scene, the DOFS is reduced by $40 \%$ for cases with cloud optical depth of 1 compared to clear-sky cases. For the results shown in this work we took a more conservative approach and did not perform $\mathrm{NH}_{3}$ retrievals for cases where the retrieved cloud optical depth was above 1. In addition, we did not also consider the impact of aerosols on the $\mathrm{NH}_{3}$ retrievals as the microwindows selected for the $\mathrm{NH}_{3}$ retrievals are from the mid-infrared portion of the spectrum that is not sensitive to aerosols.

\section{Ammonia observations and comparisons}

\subsection{Comparison methodologies}

There are a variety of ways to perform the comparisons between TES retrievals and model output or in situ observations, depending on the ultimate goal of the analysis. Before presenting the comparison results we have provided an outline of comparison approaches used in this study.

\subsubsection{Profile comparison method}

A comparison method that accounts for the a priori bias and the sensitivity and vertical resolution of the satellite retrievals is to apply the TES averaging kernel, $\mathbf{A}$, and a priori, $\boldsymbol{x}_{\mathrm{a}}$, to a model or observed profile. This method obtains an estimated profile $\boldsymbol{x}_{\text {in situ }}^{\text {est }}$ that represents what TES would measure for

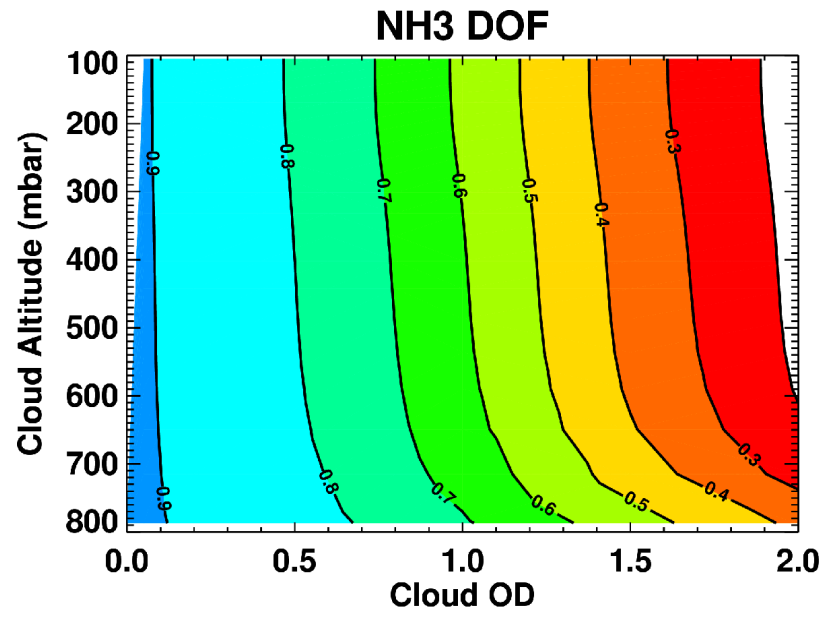

Fig. 7. TES $\mathrm{NH}_{3}$ retrieval DOFS as a function of cloud optical depth and altitude.

the same air mass sampled by the in situ measurements or model. A detailed outline of the procedure is provided in the TES Level 2 Data User's Guide (JPL, 2006). The TES standard procedure is to "map" the comparison data to the TES levels using a linear weighted average and applying the TES averaging kernel and the a priori to the mapped in situ profile:

$\boldsymbol{x}_{\text {in situ }}^{\text {est }}=\boldsymbol{x}_{\mathrm{a}}+\mathbf{A}\left(\boldsymbol{x}_{\text {in situ }}^{\text {mapped }}-x_{\mathrm{a}}\right)$.

Differences between $\boldsymbol{x}_{\mathrm{in} \text { situ }}^{\text {est }}$ and $\hat{\boldsymbol{x}}$ can then be presumed to be associated with the latter two terms in Eq. (1): the observational error on the retrieval, or systematic errors resulting from parameters which were not well represented in the forward model (e.g. temperature, interfering gases, and instrument calibration). Note that differences between $\boldsymbol{x}_{\text {in situ }}^{\text {est }}$ and $\boldsymbol{x}_{\mathrm{a}}$ go to zero in regions where the TES retrieval contains little information from the measurement, i.e. the retrieval is dominated by the a priori. The same procedure can be used to compare modeled $\mathrm{NH}_{3}$ profiles to TES.

\subsubsection{Single point comparison method}

Even though there is limited information available from the $\mathrm{NH}_{3}$ retrieval, typically $\sim 0.5-1$ DOFS, the retrieval sensitivity varies from profile to profile depending on the atmospheric state. To capture this sensitivity $\mathrm{NH}_{3}$ must be retrieved at more levels than there is information. Therefore, at any given single profile level the retrieved $\mathrm{NH}_{3} \mathrm{VMR}$ is substantially influenced by the a priori profile. The method of applying the averaging kernel and a priori profile outlined above in Sect. 3.3.1 works well for data assimilations and comparisons with model output or sonde profiles. However, if the desired application is the creation of $\mathrm{NH}_{3}$ maps or single level point comparisons from retrievals with limited amount of vertical information (e.g. 1 DOFS) then a 
different metric is needed to reduce the influence of the a priori. To address this issue, Beer et al. (2008) utilized an averaging kernel weighted volume mixing ratio (AKVMR) for TES $\mathrm{NH}_{3}$ and methanol retrievals. Payne et al. (2009) developed a representative tropospheric volume mixing ratio (RTVMR) metric for TES methane profiles, which takes into account the measurement sensitivity to map the retrieved profile onto four points (surface, peak sensitivity, tropopause, TOA) then selects the value near the peak sensitivity of the methane averaging kernel as the representative value. The mapping suitable for methane does not work well for $\mathrm{NH}_{3}$ due to its near surface peak concentrations.

For the TES $\mathrm{NH}_{3}$ point comparisons presented in this study we developed a Representative Volume Mixing Ratio (RVMR) metric, which differs from the methane RTVMR in that it maps the $\mathrm{NH}_{3}$ VMR values from all the retrieval levels onto a subset that is more representative of the information provided by the measurement (refer to Appendix B for more details). Typically for $\mathrm{NH}_{3}$ retrievals the $\mathrm{RVMR}$ represents a TES sensitivity weighted boundary layer averaged value with the influence of the a priori reduced as much as possible. The level to which the influence is reduced depends on the available retrieval information content for the observation: if there is one piece of information from a given retrieval then a single RVMR value can be generated with almost all of the a priori removed, making comparisons with in situ measurements simpler. As shown in Fig. 8, a retrieval performed with very different a priori choices (polluted vs. moderate) will still generate similar RVMR values, valid over a similar altitude range, if the DOFS from each case are not drastically different. A similar test over a range of profiles is shown in Fig. 9 in which the top panel displays the RVMR values calculated from the simulated retrieval presented in Sect. 3.2 in red, along with the results in blue from a similar retrieval from the same spectra but which did not allow polluted profiles as a priori and set the observations flagged as moderate to unpolluted. The RVMR difference decreases with increasing DOFS as expected. The differences become small above 0.65 DOFS confirming that in general the $\mathrm{NH}_{3} \mathrm{RVMR}$ is nearly independent of the a priori selection in this range (e.g. there is enough information coming from the measurement to move the RVMR value away from the a priori). Comparisons with DOFS differences up to 0.5 between the two retrievals were included in Fig. 9.

The RVMR is a "weighted" average over the region of the profile where TES is sensitive and thus is significantly lower than the maximum value. By comparing the RVMR and peak profile values from a set of simulated cases (see next section) we determined that the RVMR for cases with $\mathrm{NH}_{3}$ near the detectability level of $1 \mathrm{ppbv}$, can in general be roughly estimated as $40 \%$ of the maximum value; thus in terms of RVMR, the detectability level is $0.4 \mathrm{ppbv}$, though as stated earlier, this level is influenced by the thermal contrast and other atmospheric parameters.

\subsection{Simulated retrieval results}

To provide more insight into the performance of the TES $\mathrm{NH}_{3}$ retrieval we performed simulated retrievals for which the true profiles are known. The simulation data set contained $361 \mathrm{NH}_{3}$ profiles from a GEOS-Chem model simulation, sampled at TES global survey times and locations over the central US during July 2005. To reduce similarity of these GEOS-Chem estimates with those used to build the retrieval a priori and constraint matrices, these simulations were performed with double $\mathrm{NH}_{3}$ emissions. Radiances were simulated by inputting these GEOS-Chem profiles into the radiative transfer forward model and adding the expected TES noise for the given retrieval. Retrievals were then performed using these simulated radiances and the retrieval strategy described in Sect. 2.1. The profile comparison methodology in Sect. 3.3.1 was applied to evaluate the performance of the TES retrieval algorithm with the results shown in Fig. 10. The bias and the standard deviation from these simulated retrievals are both very small: at $825 \mathrm{hPa}$ the averaged retrieved $\mathrm{NH}_{3}$ value is $0.7 \mathrm{ppbv}$ with a bias of $0.05 \mathrm{ppbv}$ and the standard deviation $\pm 0.07 \mathrm{ppbv}$. The shape of the sum of the rows of the averaging kernel in Fig. 10 shows that the retrievals in general provide at most one piece of information, centered approximately between 700 and $900 \mathrm{hPa}$.

\subsection{Global ammonia observations and model comparisons}

Pinder et al. (2011) have shown that TES $\mathrm{NH}_{3}$ retrievals over North Carolina provided information on spatial and seasonal variability that was well correlated with in situ surface measurements. Here we present global scale results, examining the retrievals over subcontinental regions for four different months to show both the spatial and seasonal variability. Figure 11 shows $\mathrm{NH}_{3}$ RVMR results from the TES retrievals with at least $0.5 \mathrm{DOF}$ over land between $60^{\circ} \mathrm{S}$ and $60^{\circ} \mathrm{N}$ from TES Global Surveys in January, April, July and October and for years spanning 2006-2009. These initial retrievals excluded observations over water and at higher latitudes for computational expediency. Some large $\mathrm{NH}_{3}$ emission regions, or "hotspots", are readily apparent. For example, the Indus and Ganges river valleys in northern India, which sustain intense agriculture year round; eastern South America in October near the end of the biomass burning season; North America in July, especially in the agricultural Midwest; north central Africa in January owing to biomass burning.

Since one of the goals of retrieving $\mathrm{NH}_{3}$ from space is to use these retrievals to constrain emissions, we compared the TES RVMR values with GEOS-Chem output. For comparison purposes the TES observational operator (e.g. averaging kernel and a priori) and RVMR weighting function were applied to the GEOS-Chem values from 2008 (Fig. 12), with the difference between TES and GEOS-Chem RVMR values shown in Fig. 13. The comparisons are only performed 

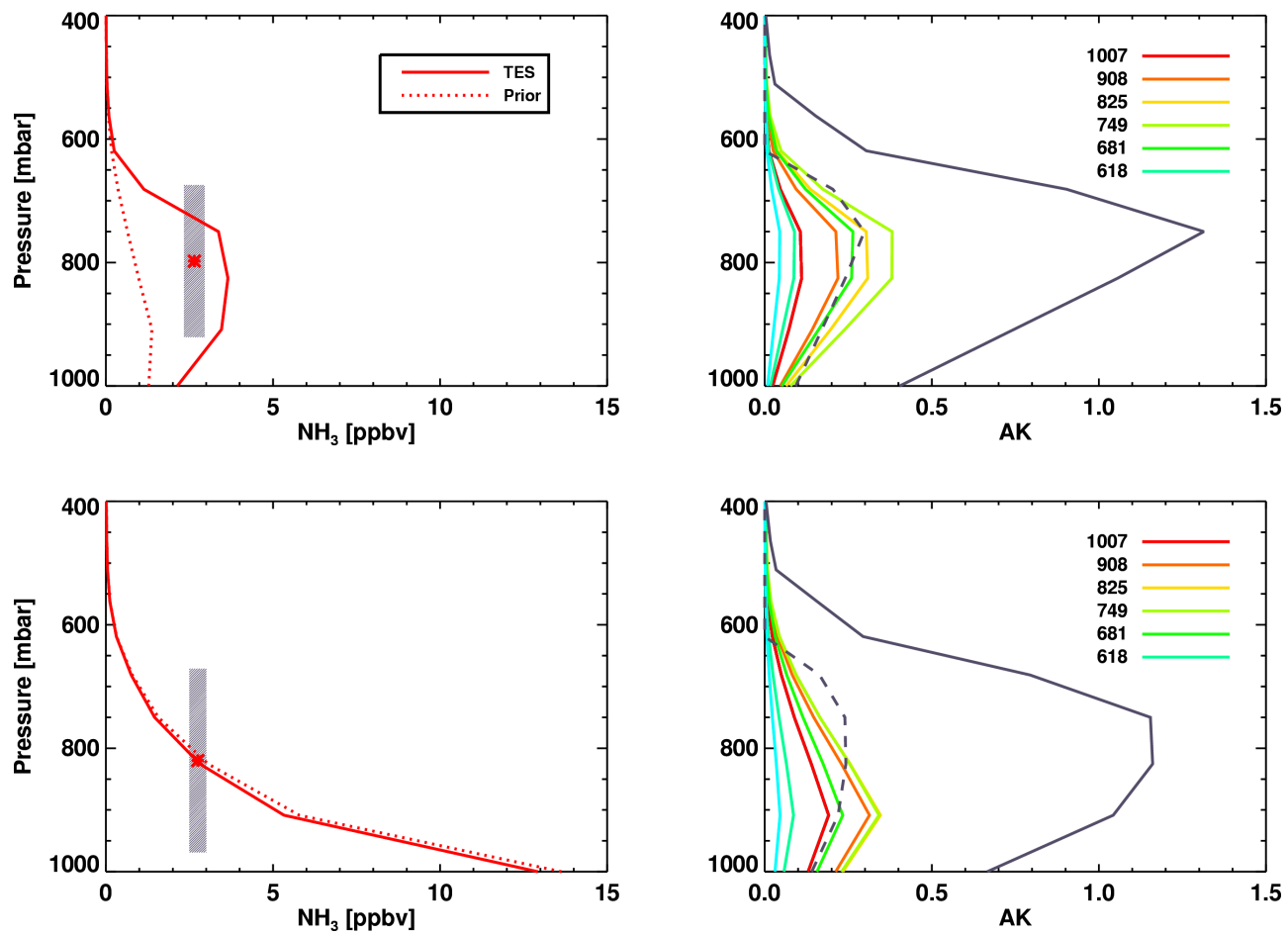

Fig. 8. Differences in retrieved profile shape due to different a priori selection choices: moderate (top) and polluted (bottom). In the left panels the solid curve is the retrieved profile, dashed curve is a priori, red star indicates RVMR at the RVMR pressure level, while the vertical extent of the grey bar indicates the range covered by the RVMR and the width shows the estimated error due to instrument noise. In the right panels the colored curves are the rows of the averaging kernel (AK), the solid grey curve is the sum of the rows of the AK, and the dashed grey curve is weighting function that maps the retrieved profile into the RVMR.
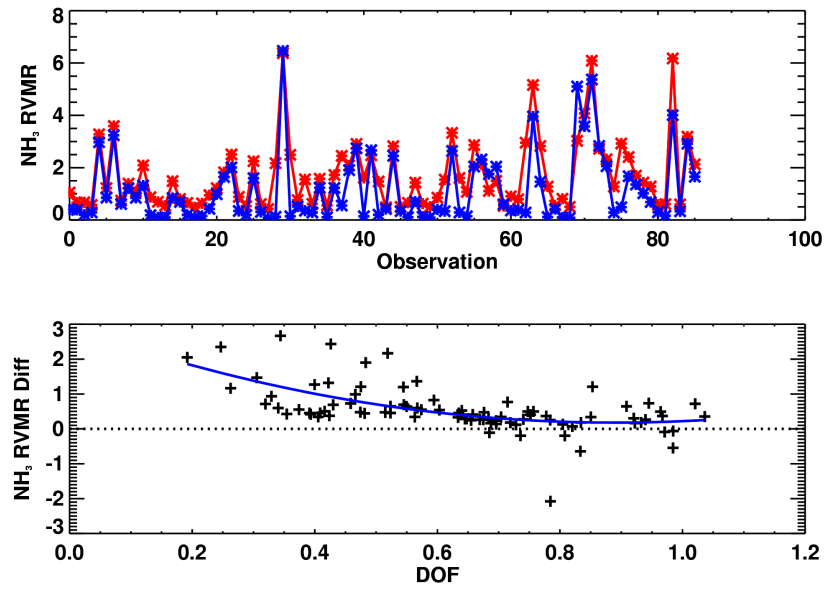

Fig. 9. RVMR values for simulated retrievals: spectra are identical, but a priori selection schemes are different. Red results are from a retrieval in which the a priori could be polluted, moderate or unpolluted, while blue results are from a retrieval in which the polluted a priori was changed to moderate, and the moderate was changed to unpolluted (top). Difference in RVMR as a function of DOF (bottom).
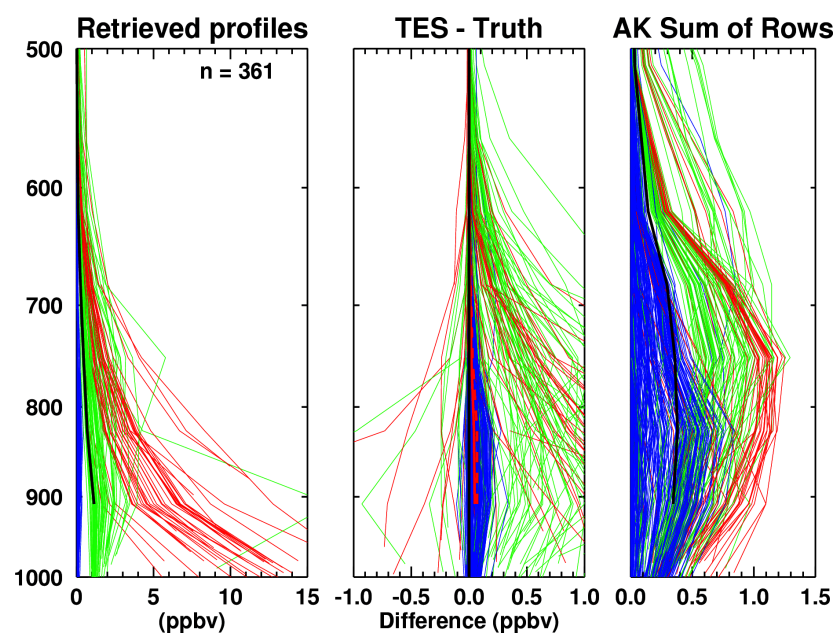

Fig. 10. Simulated retrieval results: (left) retrieved profiles, (middle) retrieved - true profiles, where the thick solid red line is mean difference and the dashed red line is standard deviation (the black line is just the reference zero line), (right) sum of the rows of the averaging kernel (black line is the average). The thin colors indicate type of true profile: polluted (red), moderate (green), unpolluted (blue). 


\section{Averaged TES NH3 RVMR: 2006-2009}
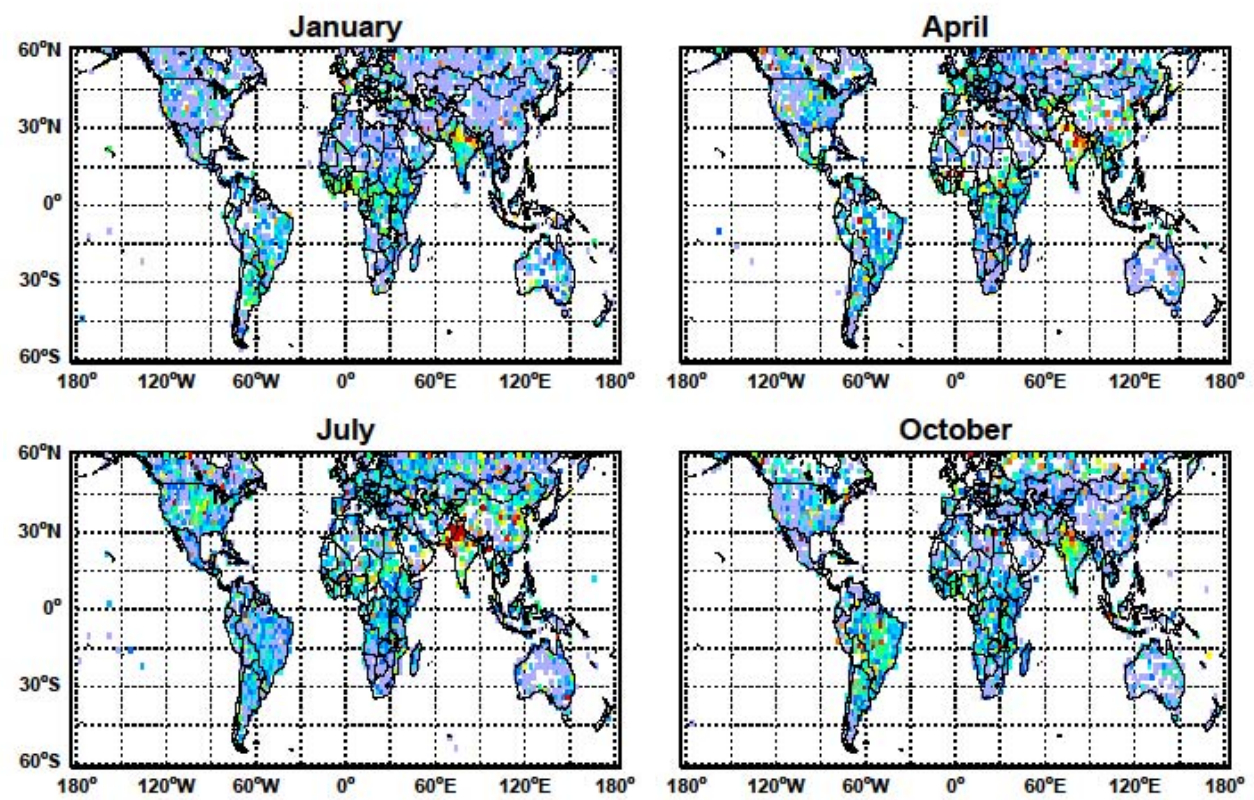

NH3 RVMR (ppbv)

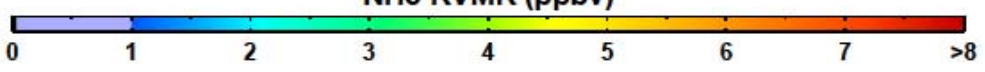

Fig. 11. TES RVMR averaged over $2 \times 2.5$ degree boxes. The white grid boxes over land are just regions without a valid TES RVMR. In this study we did not analyze observations over the ocean.

Averaged GEOS-Chem NH3 RVMR: 2006-2009
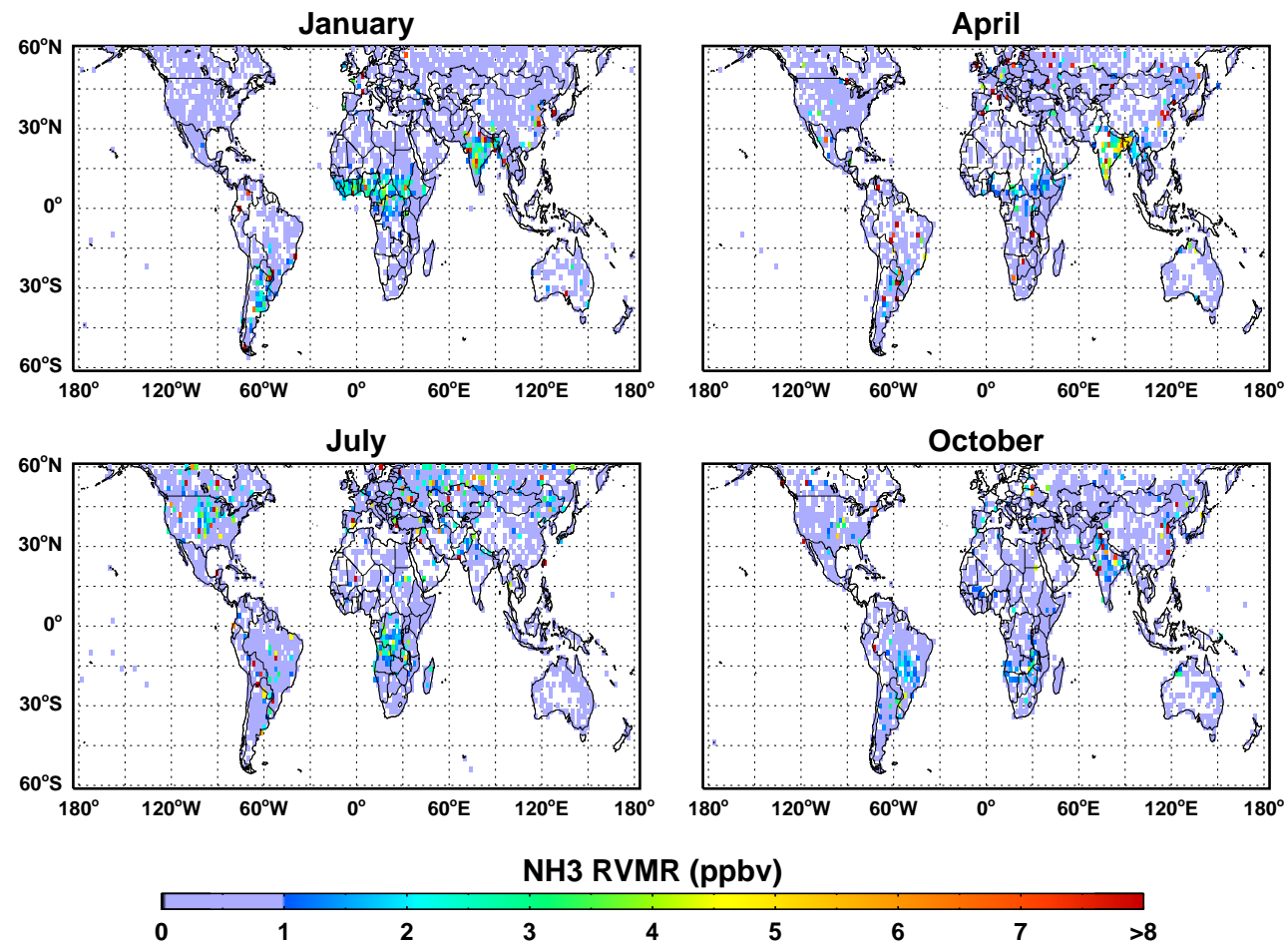

Fig. 12. GEOS-Chem with TES observational operator and RVMR applied for $2 \times 2.5^{\circ}$ averages. 


\section{Averaged NH3 RVMR: TES - GEOS-Chem: 2006-2009}
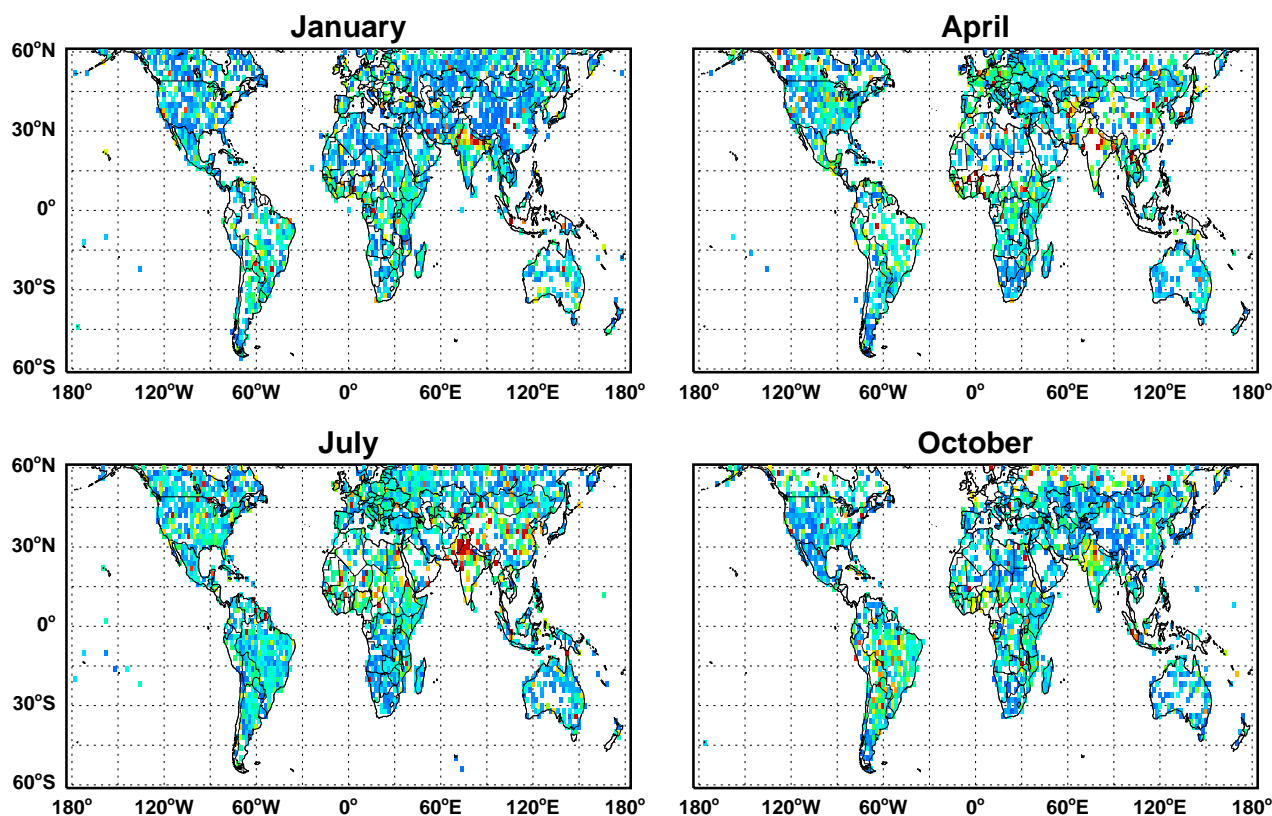

NH3 RVMR (ppbv)

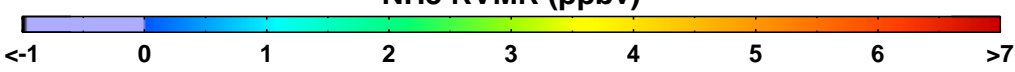

Fig. 13. Difference (TES - GEOS-Chem) RVMR plots for the $2 \times 2.5^{\circ}$ averages.

under conditions where TES is sensitive with a DOFS $\geq 0.5$ (i.e. elevated $\mathrm{NH}_{3}$ conditions). Similar hotspots are indentified between the two, yet persistence and seasonality are notably different. For example, the hotspot in northern India is prominent in both TES and GEOS-Chem during April, yet lacking from the latter in other months, most notably July. The most striking difference is that the overall magnitudes of the TES observations are higher than the GEOS-Chem model estimates and spatially more broadly ubiquitous. This result indicates that over the altitude range where TES has sensitivity to $\mathrm{NH}_{3}$ there is more $\mathrm{NH}_{3}$ measured than predicted by GEOS-Chem. This difference could be due to several factors. There could be a low bias in the model's emission database, which is primarily GEIA (Wang et al., 1998), overwritten by Streets et al. (2003) in SE Asia, EMEP in Europe (Vestreng and Klein, 2002), and Park et al. (2004) in the US. Given the potential for $\mathrm{NH}_{3}$ sources to be highly localized, there could also be a sampling bias driven by subgrid variability of $\mathrm{NH}_{3}$ within the GEOS-Chem $2^{\circ} \times 2.5^{\circ}$ model grid cells. There could also be a sampling bias in the TES measurements driven by lack of sensitivity to concentrations below 1 ppbv; however this is not likely the cause of the discrepancy because comparisons between TES and GEOS-Chem are made only in locations with successful retrievals. There is also the potential that the TES retrieval is placing the observed $\mathrm{NH}_{3}$ too high in the boundary layer, which could have a significant impact given the vertical distribution of $\mathrm{NH}_{3}$. Further study is needed to determine the origin of this difference, though it seems plausible that the difference over areas of broad source regions (e.g. SE Asia, Central Africa, Midwestern US) reflects model emissions being too low, while the differences over areas with sparse, localized sources may reflect a sampling issue.

In order to obtain more insight into the spatial and seasonal variability, twelve large areas (Fig. 14) were selected. Over each region the mean, median, the 25 and 75 percentile, number of observations, and maximum value were computed and plotted in Fig. 15 for retrievals with DOFS $\geq 0.5$ and $R V M R \geq 0.4$. Figure 16 is a similar plot created from the corresponding GEOS-Chem values. Note the different vertical scales and that the TES measurements are consistently higher than GEOS-Chem estimates, as discussed above. Nevertheless, some of the temporal and spatial features are similar and in two regions can be compared against surface measurements. Peak concentrations occur in the Northern Hemisphere summer in the US in both the TES (Fig. 15d) and GEOS-Chem (Fig. 16d) results and also in the in situ measurements (Fig. 17) (Blanchard and Tanenbaum, 2008). These higher summer values are likely due to the influence of temperature on emissions from animal manure and fertilized soil. Note that the measurements (from space and in situ) over the US mid-west show a broad warm 


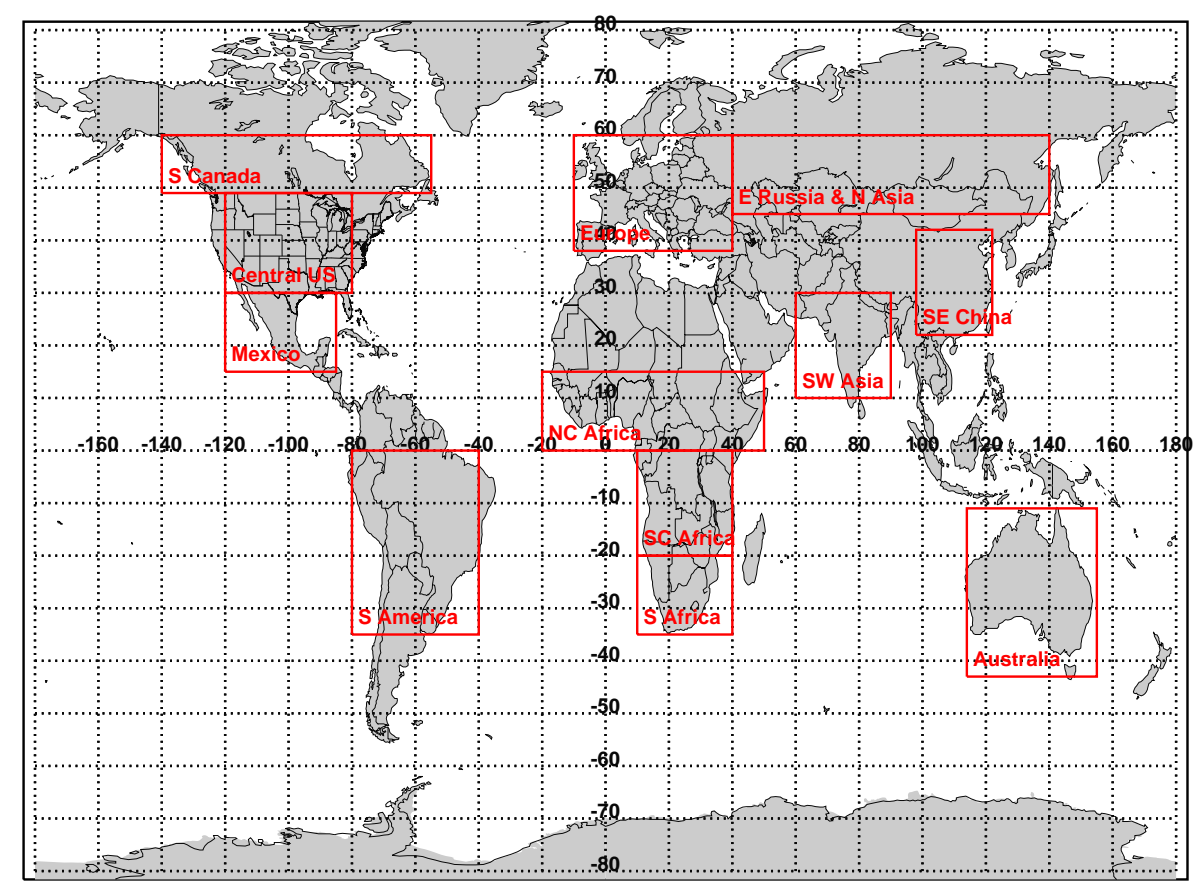

Fig. 14. Delimitation regions of interest that are grouped together for regional analysis.

weather maximum, rather than the sharp July peak predicted by GEOS-Chem. Over southeast China measurements and model estimates also show a peak in the warmer months. However the GEOS-Chem (Fig. 16f) maximum is in April, while both space-based measurements (Fig. 15f) and in situ observations in China (Ianello et al., 2010) have a July maximum. This reflects the lack of seasonality in the Streets et al. (2003) inventory used for Asia, an issue that will be corrected in subsequent future versions of GEOS-Chem, see Fisher et al. (2011). The same warm weather agricultural driver may be contributing to the peaks shown both by TES and GEOS-Chem in the Southern Hemisphere summer over South America (Fig. 15i and Fig. 16i) and Australia (Fig. 151 and Fig. 161). A different process appears to be occurring over North Central Africa, where the measurements (Fig. 15h) and model (Fig. 16h) show a January to December decrease in $\mathrm{NH}_{3}$. Finally, TES (Fig. 15g) and GEOS-Chem (Fig. 16g) both show a global maximum in $\mathrm{NH}_{3}$ over Southwest Asia, though TES sees peaks in July, while GEOSChem predicts the highest concentrations should occur in April. The strength of the $\mathrm{NH}_{3}$ signal detected by TES in this region, well above the TES sensitivity level, suggests that GEOS-Chem is significantly underestimating summer and fall emissions in this area, further supporting the need to revise the seasonality of emissions in this area.

The $\mathrm{NH}_{3}$ amounts retrieved from TES show a different correlation with the biomass burning season than the GEOS-Chem estimates (though it should be kept in mind that GEOS-Chem values reflect 2008 only). Over South America the model (Fig. 15i) and measurements (Fig. 16i) differ in the magnitude rather than the timing, with both showing significant October peaks; over Australia, where the burning season peaks in the summer, GEOS-Chem (Fig. 161) has a peak in October, while the TES measurements (Fig. 15l) reach their maximum value in January. A similar pattern in the TES/GEOS-Chem differences is evident over southern Africa (Fig. 15k and Fig. 16k). It should be noted that this pattern over southern Africa may also reflect a combination of sparse agricultural (livestock) and biogenic (compensation point) emissions. Biomass burning appears to be dominating the signal over North Central Africa, where the TES measurements (Fig. 15h), model (Fig. 16h), and in situ measurements (Adon et al., 2010) have the highest levels from December to April.

In natural and semi-natural ecosystems with very sparse or no localized $\mathrm{NH}_{3}$ sources, and which are uninfluenced by transport from source regions, the seasonality of atmospheric $\mathrm{NH}_{3}$ concentrations is driven by the influence of temperature on the compensation point of the soil and vegetation. The compensation point, which is the concentration of $\mathrm{NH}_{3}$ at which the atmosphere is in equilibrium with the vegetation/soil system, is a function of the $\mathrm{pH}$ and $\mathrm{NH}_{4}^{+}$concentration of solution within the stomatal cavity of the vegetation (leaf or needle) and soil pore water, and increases exponentially with temperature. For unmanaged, low nitrogen ecosystems, a typical leaf emission potential $(\Gamma)$ would correspond to compensation points of $\sim 0.08,0.30$ and $1.0 \mathrm{ppb}$ at 0,10 , and $20^{\circ} \mathrm{C}$, respectively (using a median value of $\Gamma=190$, Massad et al., 2010). This biogeochemical process may drive the seasonal pattern (Fig. 16c and Fig. 17c) 


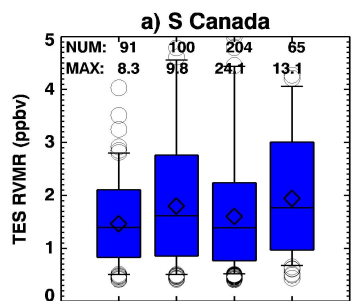

Jan. April July Oct

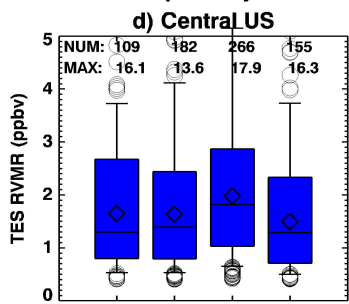

Jan. April July Oct.

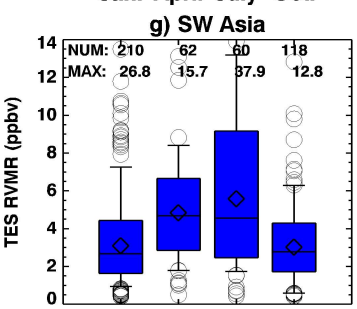

Jan. April July Oct.

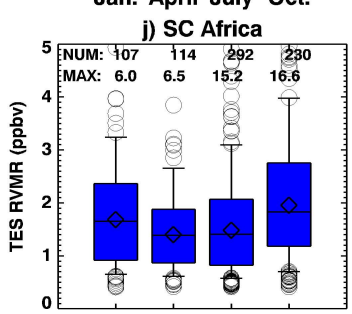

Jan. April July Oct.

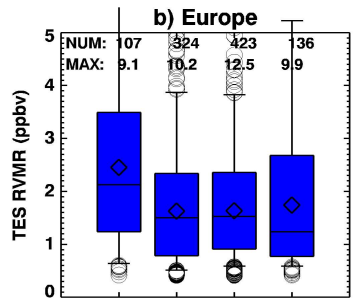

Jan. April July Oct.

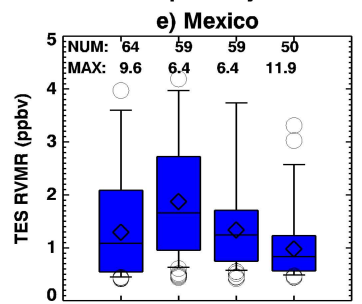

Jan. April July Oct. h) NC Africa

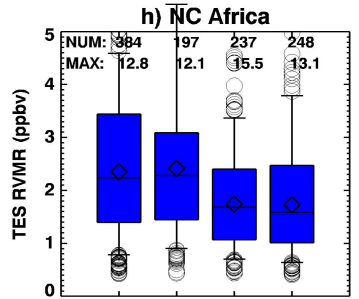

Jan. April July Oct.

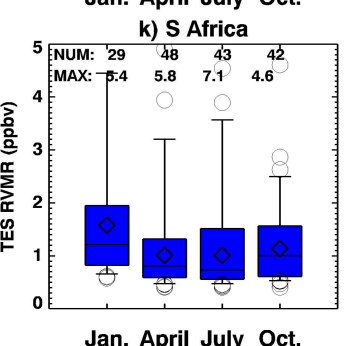

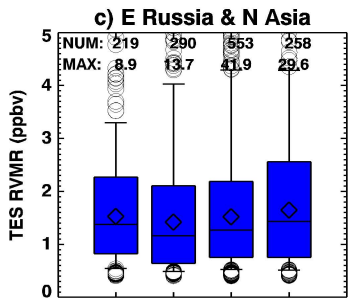

Jan. April July Oct

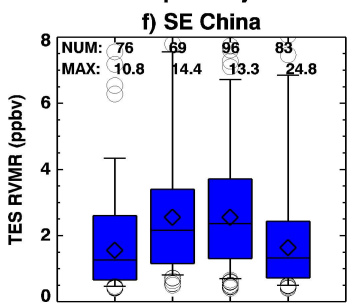

Jan. April July Oct i) $\mathrm{S}$ America

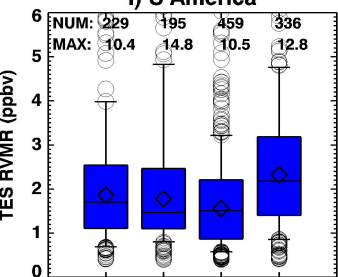

Jan. April July Oct I) Australia

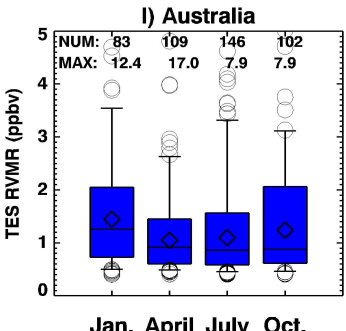

Fig. 15. TES $\mathrm{NH}_{3}$ averages in Fig. 11 for each region in Fig. 14 for the 4 yr period spanning 2006-2009. The boxes are the 25 and 75 percentile, the line in the box is the median, the diamond is the mean, whiskers are the 10 and 90 percentile and the circles are the outlier values outside the whiskers.

observed over northern Eurasia and underlies the patterns observed in other regions.

The TES results from Europe (Fig. 15b and Fig. 16b) are harder to interpret and will need further detailed evaluation. GEOS-Chem predicts a strong maximum in July, while TES shows little seasonal variability. In contrast to other regions, the TES pattern over Europe may reflect a distribution of emissions more strongly influenced by sources with less seasonal variability, such as automobile sources (Perrino et al., 2002; Whitehead et al., 2007). Southern Canada also shows a maximum in October, which needs further investigation and again may be due to sampling or some strong sources have less seasonal dependence.

\section{Summary/conclusions}

We have presented a detailed description of the TES $\mathrm{NH}_{3}$ retrieval strategy including the a priori selection algorithm and the spectral microwindows selected to reduce systematic errors from interfering species. A transformation matrix was also developed to map the retrieval level VMRs to a subset of RVMR value(s) that better represent the information provided by the satellite by reducing the influence of the a priori. This RVMR is particularly useful for applications involving simple single level maps of species with a limited amount of information, which can contain a significant amount of a priori information at any given retrieval level. The SNR sensitivity study estimated the TES level of detectability for $\mathrm{NH}_{3}$ to be a profile with a peak concentration of $1 \mathrm{ppbv}$, or equivalently an RVMR of 0.4 ppbv, provided there is significant 


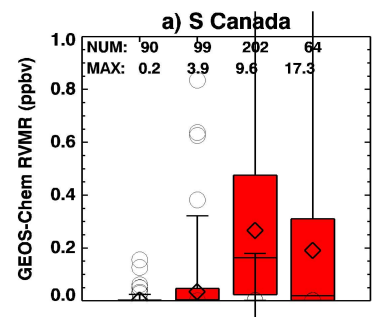

Jan. April July Oct.

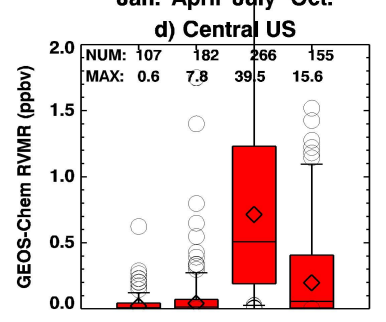

Jan. April July Oct.

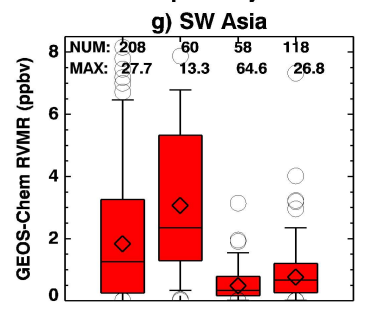

Jan. April July Oct.

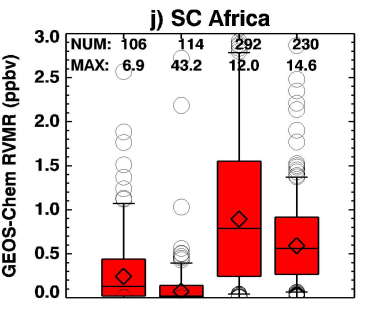

Jan. April July Oct.

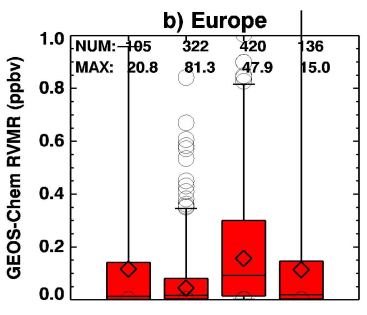

Jan. April July Oct.

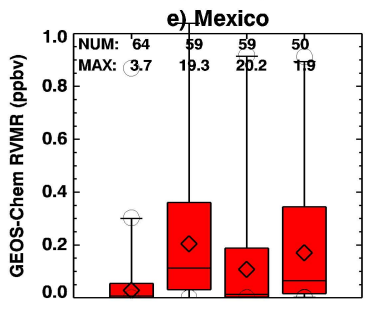

Jan. April July Oct. h) NC Africa

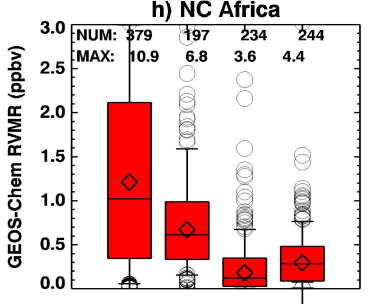

Jan. April July Oct.

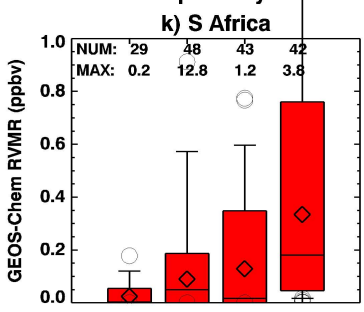

Jan. April July Oct.
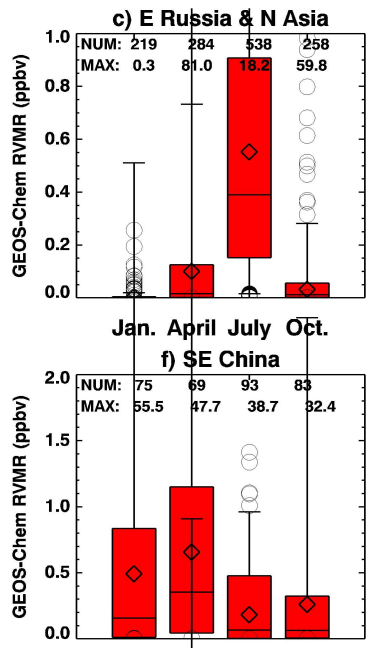

Jan. April July Oct.

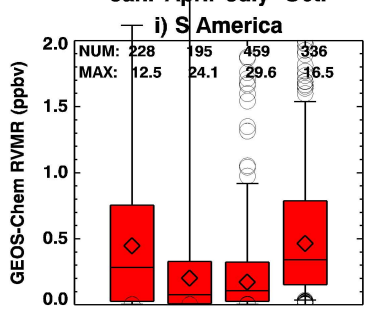

Jan. April July Oct.

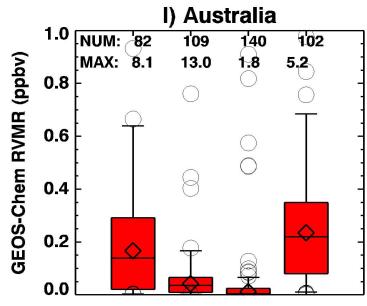

Jan. April July Oct.

Fig. 16. GEOS-Chem $\mathrm{NH}_{3}$ averages in Fig. 12 for each region in Fig. 14 for the 4 yr period spanning 2006-2009. The boxes are the 25 and 75 percentile, the line in the box is the median, the diamond is the mean, whiskers are the 10 and 90 percentile and the circles are the outlier values outside the whiskers.

thermal contrast. The cloud sensitivity study showed that the DOFS for a typical polluted $\mathrm{NH}_{3}$ profiles will be reduced by $\sim 40 \%$ for clouds with optical depth $\sim 1$ compared to clearsky cases. The newly developed retrieval algorithm was then applied to TES measurements to provide examples of the spatial and temporal variability of $\mathrm{NH}_{3}$ observations.

Comparisons of TES RVMRs to equivalent values from GEOS-Chem model simulations show important similarities and differences. The overall magnitudes of the TES measurements are consistently larger than the GEOS-Chem results. This may be explained by underestimates of emissions in GEOS-Chem or over-representation of $\mathrm{NH}_{3}$ value at the $2^{\circ} \times 2.5^{\circ}$ resolution coming from TES sampling $\mathrm{NH}_{3}$ hotspots at the subgrid level. The persistence of this difference over areas with broad source regions is indicative of the former, while the latter cause may be driving the difference over areas with relatively sparse, localized sources. Better, though far from perfect, agreement between TES and GEOSChem seasonality over biomass burning regions compared to agricultural source regions suggests the latter may be a more likely source of uncertainty in models.

An advantage of the optimal estimation retrieval approach is that the standard retrieval products (e.g. averaging kernels, error covariance matrices) facilitate direct assimilation into chemical transport models. TES $\mathrm{NH}_{3}$ retrievals over North America from both simulations and real spectra have been performed and are currently being used in an inverse modeling framework (Henze et al., 2007), which seeks to constrain the $\mathrm{NH}_{3}$ emissions using the TES measurements. This work will be described in a future paper. 

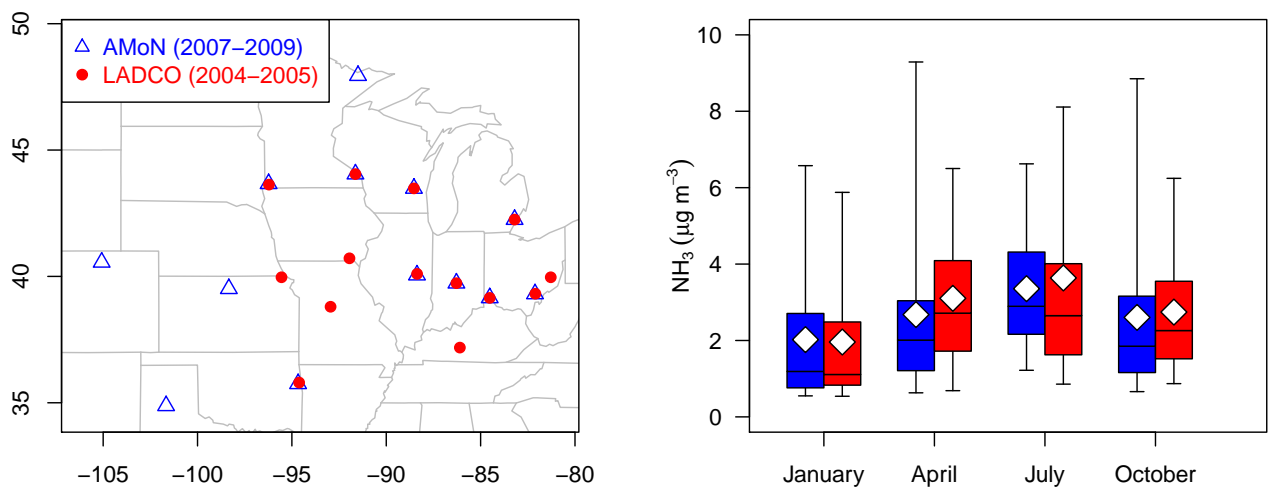

Fig. 17. Left: a map of measurement stations from the LADCO Midwest ammonia study (2004-2005) and the AMoN network (2007-2009). Right: box and whisker plot of monthly ammonia concentrations as measured at these monitoring networks, using the same notation as Fig. 15 and Fig. 16.

\section{Appendix A}

\section{TES $\mathrm{NH}_{3}$ SNR calculations}

The computations are performed as follows, using only the L1B radiances and GMAO initial guess parameters. The SNR is computed as the $\mathrm{NH}_{3}$ signal divided by the TES noise.

$$
\mathrm{SNR}=\left(\mathrm{BT}_{\mathrm{Bkgd}}-\mathrm{BT}_{\mathrm{NH} 3}\right) / \mathrm{NEdT}
$$

The $\mathrm{NH}_{3}$ signal is defined as the background brightness temperature (without $\mathrm{NH}_{3}$ ), $\mathrm{BT}_{\mathrm{Bkgd}}$, minus the brightness temperature containing $\mathrm{NH}_{3}$. In order to avoid performing a forward model calculation to determine the $\mathrm{BT}_{\mathrm{Bkgd}}$, it is estimated by obtaining the L1B brightness temperature from a nearby spectral window region.

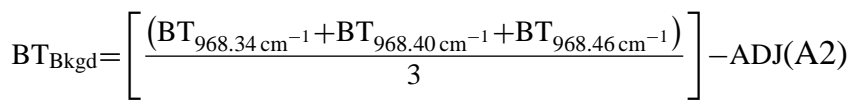

To further improve the $\mathrm{BT}_{\mathrm{Bkgd}}$ estimate a small empirical correction, ADJ, that is a function of the thermal contrast, TC, was developed using simulated data. This correction accounts for the small differences between the background brightness temperature computed in the nearby window region with the true background in the $\mathrm{NH}_{3}$ spectral region.

$\mathrm{ADJ}=0.073+0.013 \cdot \mathrm{TC}$

The thermal contrast is the initial guess (GMAO) surface temperature, $T_{\mathrm{sfc}}$, minus the near surface air temperature, Tair $_{\text {bot }}$, from the initial guess (GMAO) profile.

$\mathrm{TC}=T_{\text {sfc }}-T_{\text {air }}$ bot

The $\mathrm{NH}_{3}$ brightness temperature is simply computed as average of the 3 values around the peak of the $\mathrm{NH}_{3}$ signal,

$\mathrm{BT}_{\mathrm{NH} 3}=\frac{\left(\mathrm{BT}_{967.28 \mathrm{~cm}^{-1}}+\mathrm{BT}_{\left.967.34 \mathrm{~cm}^{-1}+\mathrm{BT}_{967.40 \mathrm{~cm}^{-1}}\right)}^{3}\right.}{3}$
The NEdT is computed directly from the provided TES L1B NESR.

NedT $=$ NESR $\cdot \frac{\partial B T}{\partial R}$

where the NESR is average over the $\mathrm{BT}_{\mathrm{NH}_{3}}$ spectral and divided by the SQRT(3.0) and the $d \mathrm{BT} / d R$ is computed using the mean radiance and wavenumber of the $\mathrm{BT}_{\mathrm{NH}_{3}}$ spectral points.

The computed SNR and the thermal contrast determine a point in the plane shown in Fig. 5. The distance from the point to each of the straight-line fits is calculated using Eq. (A7) and the smallest distance determines the a priori type and the initial guess profile. If the SNR is less than 0.5, the type is always returned as unpolluted. If the type is unpolluted, the initial guess is set to moderate to avoid falling into null space,

$$
\begin{aligned}
& x=(\mathrm{SNR}+\mathrm{TC} / \alpha-\beta) /(\alpha+1 . / \alpha) \\
& y=\alpha \cdot x+\beta \\
& d=\sqrt{(x-\mathrm{TC})^{2}+(y-\mathrm{SNR})^{2}}
\end{aligned}
$$

where, $\alpha=[0.001,0.225,0.762]$, and $\beta=[0.116,-0.126$, $0.270]$.

\section{Appendix B}

\section{Representative Volume Mixing Ratio (RVMR)}

In this section we describe the process used to map the retrieval level values (10-13 levels), which individually can contain a significant amount of a priori, to a reduced number of RVMR values, which have less a priori influence. Instead of using a typical linear mapping, this transformation (or "mapping") matrix is constructed based on the information content from the various retrieval levels. The transformation matrix is generated from an iterative rank procedure going from the greatest to the least information content estimated 

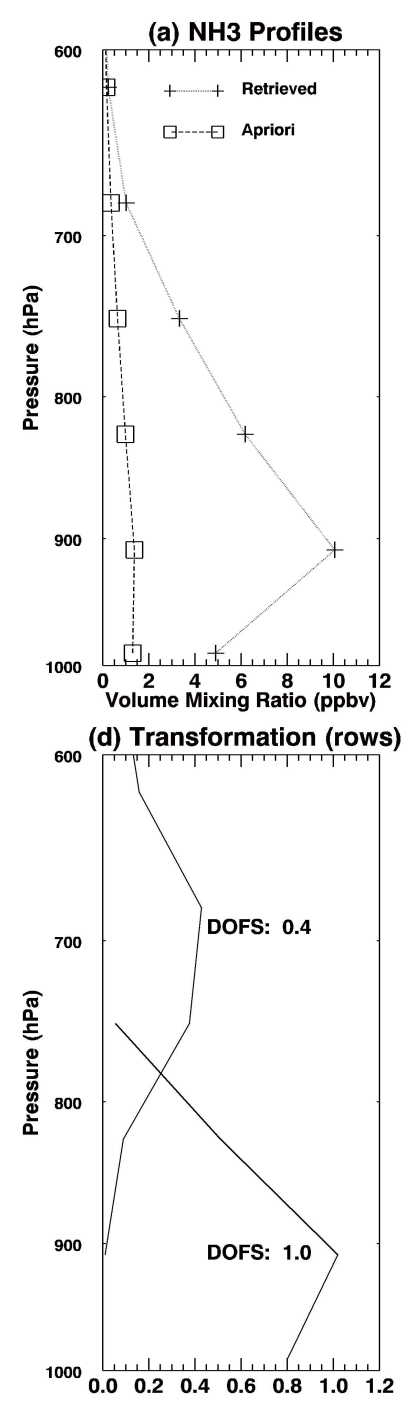
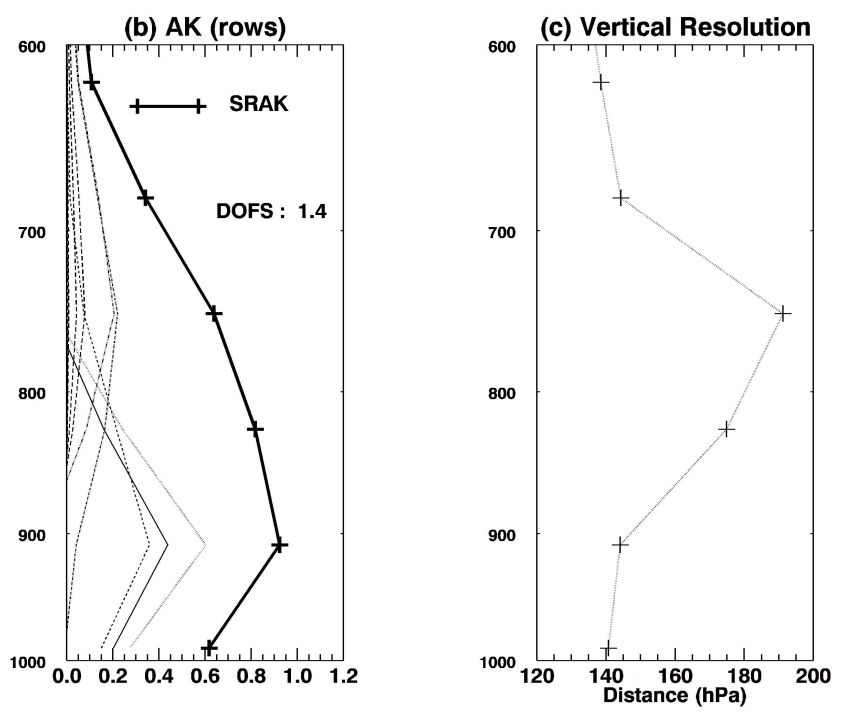

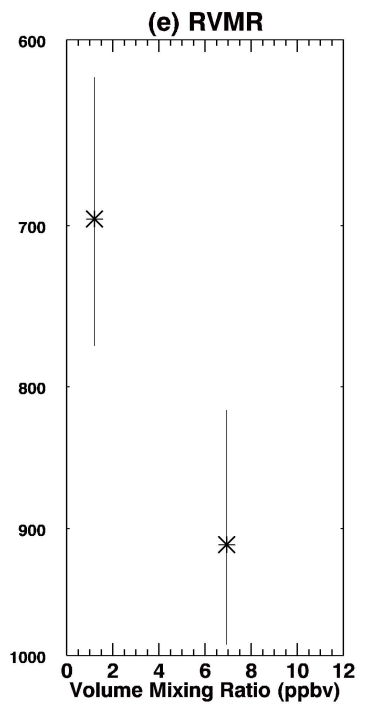

Fig. 18. These plots demonstrate the generation of the RVMR values from an example $\mathrm{TES} \mathrm{NH}_{3}$ retrieved profile where: (a) shows the example retrieved and a priori profiles; (b) the corresponding rows of the averaging kernel, with the sum of the rows of the averaging kernel (SRAK) in the thick solid line and reported degrees of freedom for signal (DOFS) for the example; (c) the vertical resolution at each of the retrieved levels; (d) the resulting rows of the transformation matrix used to produce the RVMR values; and (e) the resultant RVMR values marked with a star and vertical lines showing their resolution.

from the sum of the rows of the averaging kernel (SRAK). An example of the procedure is presented in Fig. 18. Figure 18a shows the retrieved and apriori $\mathrm{NH}_{3}$ values at the 10 retrieval levels. Figure $18 \mathrm{~b}$ contains the individual averaging kernels of each original retrieval level and the SRAK. The trace of the averaging kernel matrix provides the total amount of information or degrees of freedom for signal (DOFS). For this retrieval example there are 1.4 DOFS spread across 10 retrieval levels. The vertical resolution of each retrieved level is computed as the FWHM of the corresponding averaging kernel for that level. These values are computed and plotted in Fig. 18c. Rows of the averaging kernels from the retrieval are combined in an iterative rank order procedure to con- struct a transformation matrix used to generate the RVMR. The procedure starts by selecting the pressure level corresponding to the peak of the SRAK. The vertical resolution of the selected level (FWHM of the averaging kernel) is used to determine the vertical extent in which the averaging kernels are combined, and thus the top and bottom of the resulting RVMR values. In other words, the rows of all the averaging kernels corresponding to pressure levels within this vertical extent are combined to form a single row of the transformation matrix. These levels are then removed from consideration for the next peak selection and the procedure is repeated creating additional rows of the transformation matrix until the remaining retrieval levels contain less then a specified 


\section{Averaged TES RVMR Pressure: 2006-2009}
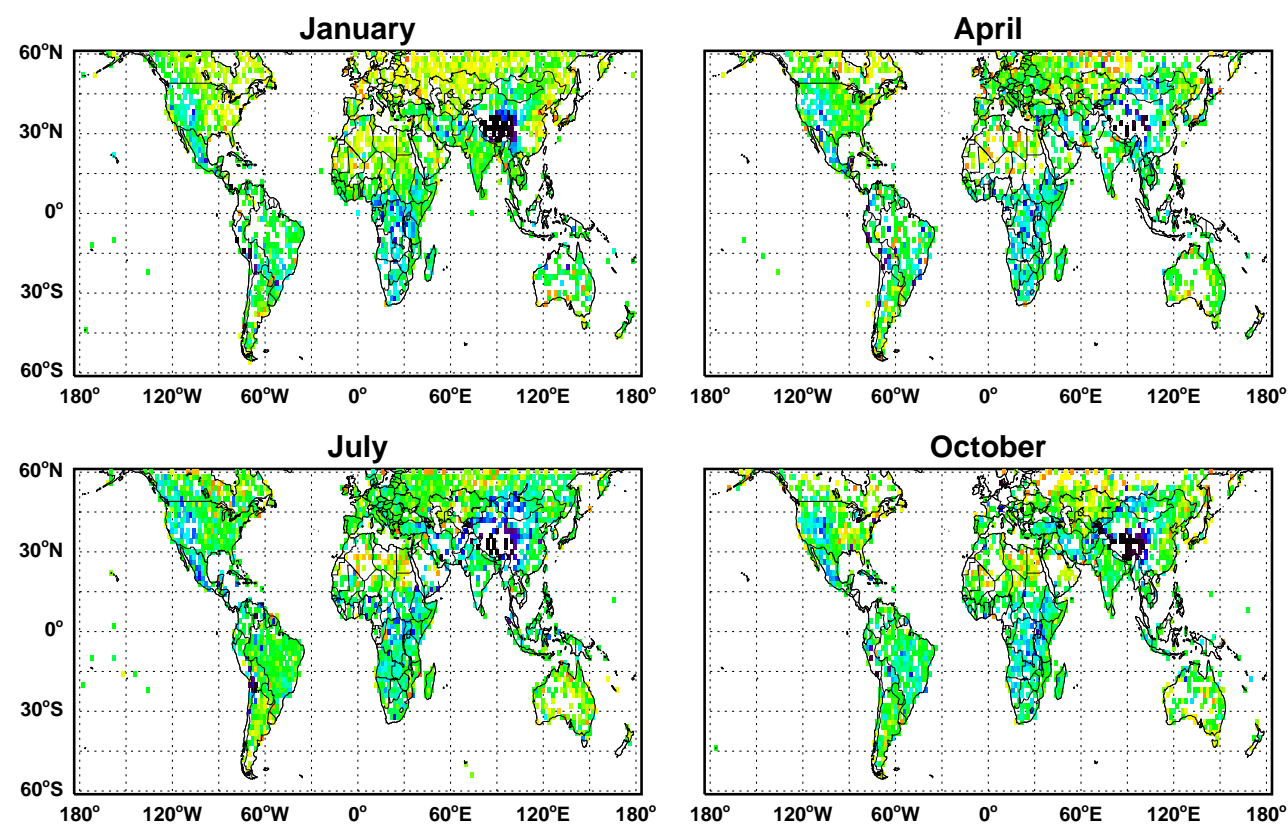

RVMR Pressure (hPa)

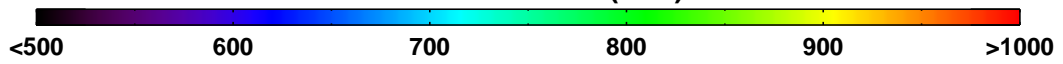

Fig. 19. TES RVMR pressure levels averaged over $2 \times 2.5^{\circ}$ boxes corresponding to the RVMR values in Fig. 11 .

Averaged TES DOFS: 2006-2009
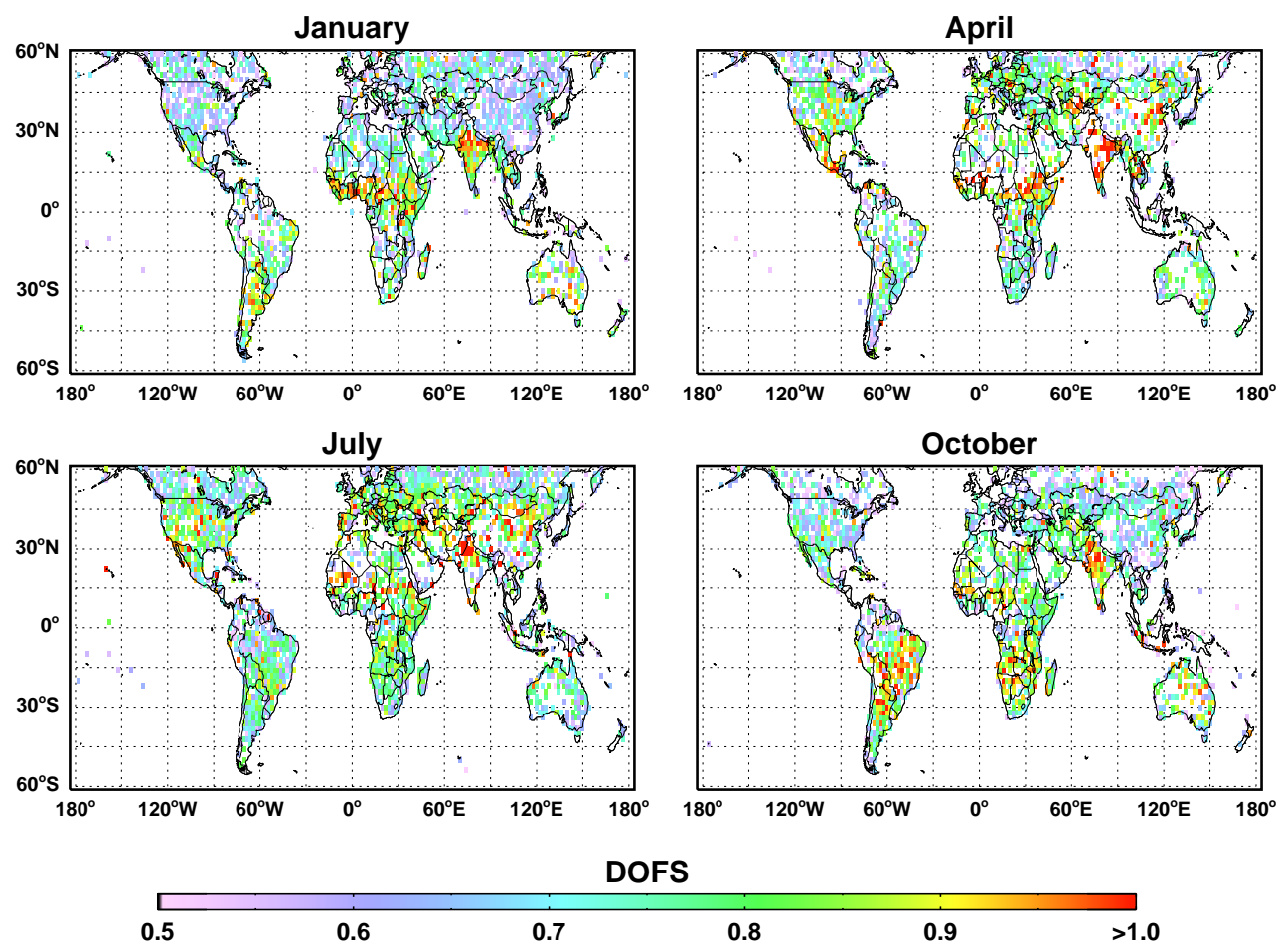

Fig. 20. The TES retrieval degrees of freedom averaged over the $2 \times 2.5^{\circ}$ boxes corresponding to the RVMR values in Fig. 11 . 


\section{Averaged TES RVMR Vertical Resolution: 2006-2009}
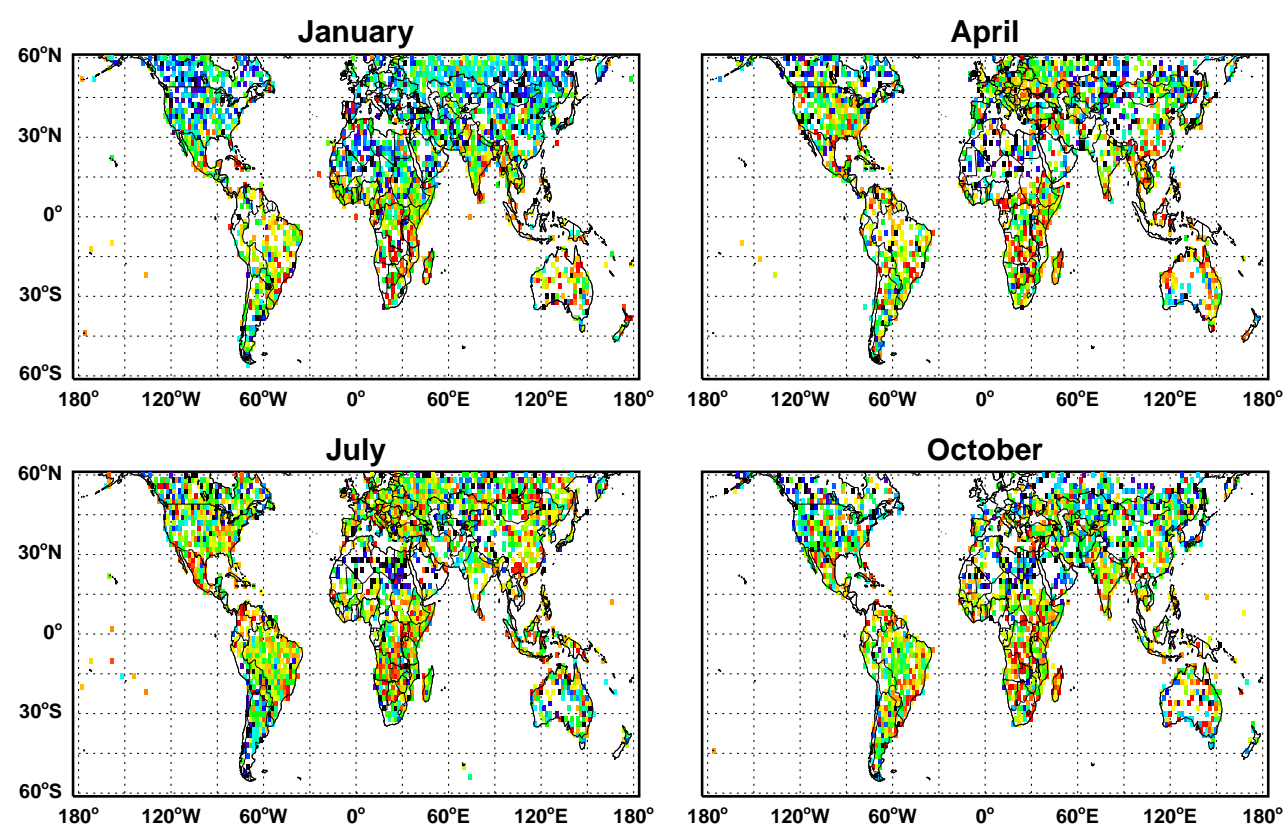

RVMR Vertical Resolution (KM)

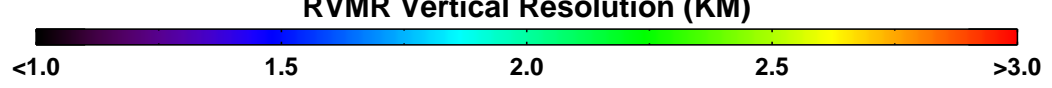

Fig. 21. The TES retrieval vertical resolution averaged over the $2 \times 2.5^{\circ}$ boxes corresponding to the RVMR values in Fig. 11 .

minimum DOFS threshold value (e.g. 0.1 DOFS). Note that in order to conserve the total retrieval information content the contributions from overlap regions between adjacent rows in the transformation matrix are distributed piece-wise linearly. Figure 18d shows the resulting rows of the transformation matrix generated from combining the averaging kernels in (Fig. 18e). The transformation matrix is then normalized and convolved with the retrieved parameters (e.g. retrieved $\mathrm{NH}_{3}$ "profile") to provide RVMR values (Fig. 18e) with DOFS, resolution, and the bottom and top pressure levels.

\section{Appendix C}

\section{Additional TES retrieval parameters from the global comparisons}

To provide additional insight on the global TES retrieved RVMR values, Figs. 19, 20, and 21, contain the RVMR peak pressure level, the retrieval degrees of freedom for signal (information content), and the vertical resolution corresponding to the RVMR values in Fig. 11 for the four seasons.

\section{Appendix D}

\section{Distribution functions from the global comparisons}

A different perspective on the retrievals from the TES Global Surveys can be obtained by examining the density distribution of the RVMR values (Fig. 22). The distribution is strongly skewed to low values, except over southwest Asia. In most cases we were able to fit a Weibull PDF very successfully to the plotted distributions. The Weibull PDF is characterized by a peak at low values and a long tail, and is used to model datasets where most values are small, but there are statistically significant occasional high values that are not outliers that skew the distribution and contain important information on the system under study. A typical example is the distribution of wind speeds at a given location; in general the wind speed is fairly low, but it is high wind days that are of greatest interest. Similarly for the measured $\mathrm{NH}_{3}$ distributions, most sampled locations are characterized by low RVMR values (less than 2 ppbv), but the sparse "hotspots" are statistically significant and of greatest interest.

Southwest Asia presents a very different distribution, suggesting that great extents of this region are characterized by high $\mathrm{NH}_{3}$ concentrations. 

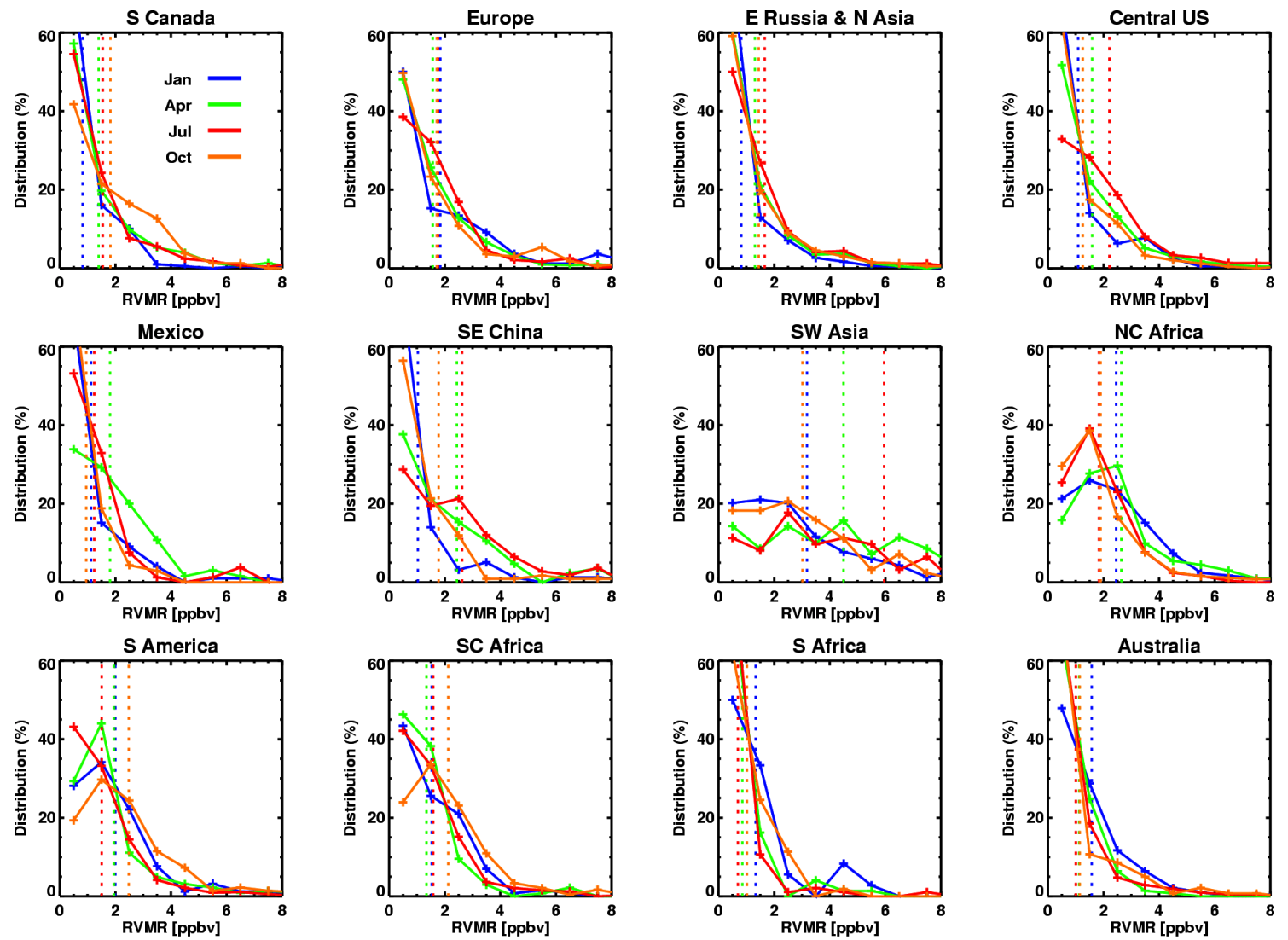

Fig. 22. Density distribution of the TES RVMRs for each region and month; histogram bin size is 1.0; dashed lines indicate mean values for the corresponding month.

Acknowledgements. We would like to dedicate this article to our good friend and colleague Curtis Rinsland who passed away during review process of this publication. He was a very dedicated and accomplished scientist who will be greatly missed by our scientific community. We would like to thank Tom Connor, Alan Lipton, Jean-Luc Moncet, and Gennady Uymin of AER for building an OSS version for TES. We would also like to thank Reinhard Beer and Shepard A. (Tony) Clough for their initial retrieval support. Research was partially supported by the Jet Propulsion Laboratory, California Institute of Technology under contract to the National Aeronautics and Space Administration (NASA). Contributions at CU Boulder recognize support from NASA grant NNX10AG63G and EPA-STAR RD83455901. Research at NASA Langley Research Center was supported under a proposal funded by NASA. L. Clarisse is supported as a Postdoctoral Researcher with F.R.S.-FNRS. Although this paper has been reviewed by both EC and EPA and approved for publication, it does not necessarily reflect EPA or EC policies or views.

Edited by: F. Dentener

\section{References}

Adams, P. J., Seinfeld, J. H., and Koch, D. M.: Global concentrations of tropospheric sulfate, nitrate, and ammonium aerosol simulated in a general circulation model, J. Geophys. Res., 104, 13791-13823, 1999.

Adon, M., Galy-Lacaux, C., Yoboué, V., Delon, C., Lacaux, J. P., Castera, P., Gardrat, E., Pienaar, J., Al Ourabi, H., Laouali, D., Diop, B., Sigha-Nkamdjou, L., Akpo, A., Tathy, J. P., Lavenu, F., and Mougin, E.: Long term measurements of sulfur dioxide, nitrogen dioxide, ammonia, nitric acid and ozone in Africa using passive samplers, Atmos. Chem. Phys., 10, 7467-7487, doi:10.5194/acp-10-7467-2010, 2010.

Beer, R., Shephard M. W., Kulawik, S. S., Clough, S. A., Eldering, A., Bowman, K. W., Sander, S. P., Fisher, B. M., Payne, V. H., Luo, M., Osterman, G. B., and Worden, J. R.: First satellite observations of lower tropospheric ammonia and methanol, Geophys. Res. Lett., 35, L09801, doi:10.1029/2008GL033642, 2008.

Blanchard, C. L. and Tanenbaum, S.: Analysis of Inorganic Particulate Matter Formation in the Midwestern United States Final Report Prepared for Lake Michigan Air Directors Consortium, 30 November 2008, Albany, CA, USA, 2008.

Bouwman, A. F., Lee, D. S., Asman, W. A. H., Dentener, F. J., VanderHoek, K. W., and Olivier, J. G. J.: A global high-resolution emission inventory for ammonia, Global Biogeochem. Cy., 11, 
561-587, 1997

Burgess, A. B., Budhia, A., Grainer, B. G., and Stephenson, D.: Progress in tropospheric ammonia retrieval from the MIPAS satellite instrument, Adv. Space Res., 37, 2218-2221, 2006.

Bowman, K. W., Rodgers, C. D., Sund-Kulawik, S., Worden, J., Sarkissian, E., Osterman, G., Steck, T., Luo, M., Eldering, A., Shephard, M. W., Worden, H., Clough, S. A., Brown, P. D., Rinsland, C. P., Lampel, M., Gunson, M., and Beer, R.: Tropospheric emission spectrometer: Retrieval method and error analysis, IEEE T. Geosci. Remote, 44, 1297-1307, doi:10.1109/TGRS.2006.871234, 2006.

Carfrae, J. A., Sheppard, L. J., Raven, J., Stein, W., Leith, I. D., Theobald, A., and Crossley, A.: Early effects of atmospheric ammonia deposition on Calluna vulgaris (L.) hull growing on an ombrotrophic peat bog, Water Air Soil Pollut. Focus, 4, 229-239, 2004.

Charlson, R. J., Langner, J., Rodhe, H., Leovy, C. B., and Warren, S. G.: Perturbation of the Northern-Hemisphere Radiative Balance by Backscattering from Anthropogenic Sulfate Aerosols, Tellus A, 43, 152-163, 1991.

Clough, S. A., Shephard, M. W., Mlawer, E. J., Delamere, J. S., Iacono, M. J., Cady-Pereira, K., Boukabara, S., and Brown, R. D.: Atmospheric radiative transfer modeling: a summary of the AER codes, J. Quant. Spectrosc. Ra., 91, 233-244, 2005.

Clarisse, L., Clerbaux, C., Dentener, F., Hurtmans, D., and Coheur, P.-F.: Global ammonia distribution derived from infrared satellite observations, Nature Geosci., 2, 479-483, doi:10.1038/ngeo551, 2009.

Clarisse, L., Shephard, M. W., Dentener, F., Hurtmans, D., CadyPereira, K., Karagulian, F., Van Damme, M., Clerbaux, C., and Coheur P.-F.: Satellite monitoring of ammonia: A case study of the San Joaquin Valley, J. Geophys. Res., 115, D13302, doi:10.1029/2009JD013291, 2010.

Clough, S. A., Shephard, M. W., Worden, J., Brown, P. D., Worden, H. M., Luo, M., Rodgers, C. D., Rinsland, C. P., Goldman, A., Brown, L., Kulawik, S. S., Eldering, A., Lampel, M. C., Osterman, G., Beer, R., Bowman, K., Cady-Pereira, K. E., and Mlawer, E. J.: Forward Model and Jacobians for Tropospheric Emission Spectrometer Retrievals, IEEE T. Geosci. Remote, 44, 1308-1323, 2006.

Duncan, B. N., Martin, R. V., Staudt, A. C., Yevich, R., and Logan, J. A.: Interannual and seasonal variability of biomass burning emissions constrained by satellite observations, J. Geophys. Res., 108, 4100, doi:10.1029/2002JD002378, 2003

Eldering, A., Kulawik, S. S., Worden, J., Bowman, K., and Osterman, G.: Implementation of cloud retrievals for TES atmospheric retrievals: 2. Characterization of cloud top pressure and effective optical depth retrievals, J. Geophys. Res., 113, D16S37, doi:10.1029/2007JD008858, 2008.

Erisman, J. W., Galloway, J. A., Sutton, M. S., Klimont, Z., and Winiwater, W.: How a century of ammonia synthesis changed the world, Nature Geosci., 1, 636-639, 2008.

Fisher, J. A., Jacob, D. J., Wang, Q., Bahreini, R., Carouge, C. C., Cubison, M. J., Dibb, J. E., Diehl, T., Jimenez, J. L., Leibensperger, E. M., Meinders, M. B. J., Pye, H. O. T., Quinn, P. K., Sharma, S., van Donkelaar, A., and Yantosca, R. M.: Sources, distribution, and acidity of sulfateammonium aerosol in the Arctic in winter-spring, Atmos. Environ., doi:10.1016/j.atmosenv.2011.08.030, in press, 2011.
Galloway, J. N., Townsend, A. R., Erisman, J. W., Bekunda, M., Cai, Z., Freney, J. R., Martinelli, L. A., Seitzinger, S. P., and Sutton, M. A.: Transformation of the Nitrogen Cycle: Recent Trends, Questions, and Potential Solutions, Science, 320, 889892, doi:10.1126/science.1136674, 2008.

Gilliland, A. B., Dennis, R. L., Roselle, S. J., and Pierce, T. E.: Seasonal $\mathrm{NH}_{3}$ emission estimates for the eastern United States based on ammonium wet concentrations and an inverse modeling method, J. Geophys. Res., 108, 4477, doi:10.1029/2002JD003063, 2003.

Gilliland, A. B., Appel, K. W, Pinder, R. W., and Dennis, R. L.: Seasonal $\mathrm{NH}_{3}$ emissions for the continental United States: Inverse model estimation and evaluation, Atmos. Environ., 40, 49864998, 2006.

Henze, D. K., Hakami, A., and Seinfeld, J. H.: Development of the adjoint of GEOS-Chem, Atmos. Chem. Phys., 7, 2413-2433, doi:10.5194/acp-7-2413-2007, 2007.

Henze, D. K., Seinfeld, J. H., and Shindell, D. T.: Inverse modeling and mapping US air quality influences of inorganic $\mathrm{PM}_{2.5}$ precursor emissions using the adjoint of GEOS-Chem, Atmos. Chem. Phys., 9, 5877-5903, doi:10.5194/acp-9-5877-2009, 2009.

Ianniello, A., Spataro, F., Esposito, G., Allegrini, I., Rantica, E., Ancora, M. P., Hu, M., and Zhu, T.: Occurrence of gas phase ammonia in the area of Beijing (China), Atmos. Chem. Phys., 10, 9487-9503, doi:10.5194/acp-10-9487-2010, 2010.

JPL, TES Level 2 Data User's Guide, edited by Osterman, G., available online at: http://tes.jpl.nasa.gov/uploadedfiles/TES_ L2_Data_Users_Guide-1.pdf, 2006.

Kleiner, I., Tarrago, G., Cottaz, C., Sagui, L., Brown, L. R., Poynter, R. L., Pickett, H. M., Chen, P., Pearson, J. C., Sams, R. L., Blake, G. A., Matsuura, S., Nemtchinov, V., Varanasi, P., Fusina, F., and Dilonardo, G. Di.: NH3 and $\mathrm{PH}_{3}$ parameters: the 2000 HITRAN update and new parameters J. Quant. Spectrosc. Ra., 82, 293312, 2003.

Kulawik, S. S., Worden, J., Eldering, A., Bowman, K., Gunson, M., Osterman, G. B., Zhang, L., Clough, S. A., Shephard, M. W., and Beer, R.: Implementation of cloud retrievals for Tropospheric Emission Spectrometer (TES) atmospheric retrievals: part 1. Description and characterization of errors on trace gas retrievals, J. Geophys. Res., 111, D24204, doi:10.1029/2005JD006733, 2006.

Moncet, J.-L., Uymin, G., Lipton, A. E., and Snell, H. E.: Infrared radiance modeling by optimal spectral sampling, J. Atmos. Sci., 65, 3917-3934, 2008.

Massad, R.-S., Nemitz, E., and Sutton, M. A.: Review and parameterisation of bi-directional ammonia exchange between vegetation and the atmosphere, Atmos. Chem. Phys., 10, 10359-10386, doi:10.5194/acp-10-10359-2010, 2010.

Paerl, H. W., Dennis, R. L., and Whitall, D. R.,: Atmospheric deposition of nitrogen: Implications for nutrient over-enrichment of coastal waters, Estuaries, 24, 667-693, 2002.

Park, R. J., Jacob, D., Field, B. D., Yantosca, R., and Chin, M.: Natural and transboundary pollution influences on sulfatenitrate-ammonium aerosols in the United States: Implications for policy, J. Geophys. Res.-Atmos., 109, D15204, doi:10.1029/2003JD004473, 2004.

Payne, V. H., Clough, S. A., Shephard, M. W., Nassar, R., and Logan, J. A.: Information-centered representation of retrievals with limited degrees of freedom for signal: Application to methane 
from the Tropospheric Emission Spectrometer, J. Geophys. Res., 17, 1095, doi:10.1029/2008JD010155, 2009.

Perrino, C., Catrambone, M., Di Menno Di Bucchianico, A., and Allergrini, I.: Gaseous ammonia in the urban area of Rome, Italy and its relationship with traffic emissions, Atmos. Environ., 36, 5385-5394, 2002.

Pinder, R. W., Gilliand, A. B., and Dennis, R. L.: Environmental impact of atmospheric $\mathrm{NH}_{3}$ emissions under present and future conditions in the eastern United States, Geophys. Res. Lett., 35, L12808, doi:10.1029/2008GL033732, 2008.

Pinder, R. W., Walker, J. T., Bash, J. O., Cady-Pereira, K. E., Henze, D. K., Luo, M., and Shephard, M. W.: Quantifying spatial and temporal variability in atmospheric ammonia with in situ and space-based observations, Geophys. Res. Lett., 38, L04802, doi:10.1029/2010GL046146, 2011.

Pope, C. A.: Epidemiology of fine particulate air pollution and human health: Biologic mechanisms and who's at risk?, Environ. Health Perspect., 108, 713-723, 2000.

Rodgers, C. D.: Inverse methods for atmospheric Sounding: Theory and Practice, World Sci., Hackensack, NJ, 2000.

Rothman, L. S., Barbe, A., Benner, D. C., Brown, L. R., CamyPeyret, C., Carleer, M. R., Chance, K., Clerbeaux, C., Dana, V., Devi, V. M., Fayt, A., Flaud, J.-M., Gamache, R. R., Goldman, A., Jacquemart, D., Jucks, K. W, Lafferty, W. J, Mandin J.-Y., Massie, S. T., Newnham, D. A., Perrin, A., Rinsland, C. P., Schroeder, J., Smith, M. A., Tang, K., Toth, R. A., Vander Auwera, J., Varanasi, P., and Yoshino, K.: The HITRAN molecular spectroscopic database: edition 2000 including updates through 2001, J. Quant. Spectrosc. Ra., 82, 5-44, 2003.

Rothman, L. S., Jaquemart, D., Barbe, A., Benner, C. D., Birk, M., Brown, L. R., Carleer, M. R., Chackerian, C., Chance, K., Coudert, L. H., Dana, V., Devi, V. M., Flaud, J.-M., Gamache, R. R., Goldman, A., Hartmann, J.-M., Jucks, K. W., Maki, A. G., Mandin, J.-Y., Massie, S. T., Orphal, J., Perrin, A., Rinsland, C. P., Smith, M. A. H., Tennyson, J., Tolchenov, R. N., Toth, R. A., Vander Auwera, J., Varanasi, P., and Wagner, G.: The HITRAN 2004 molecular spectroscopic database, J. Quant. Spectrosc. Ra., 96, 139-204, 2005.

Seinfeld, J. H. and Pandis, S. N.: Atmospheric Chemistry and Physics, John Wiley, Hoboken, NJ, 1988.
Shephard, M. W., Worden, H. M., Cady-Pereira, K. E., Lampel, M., Luo, M., Bowman, K. W., Sarkissian, E., Beer, R., Rider, D. M., Tobin, D. C., Revercomb, H. E., Fisher, B. M., Tremblay, D., Clough, S. A., Osterman, G. B., and Gunson, M.: Tropospheric Emission Spectrometer Spectral Radiance Comparisons, J. Geophys. Res., 113, D15S05, doi:10.1029/2007JD008856, 2008.

Shephard, M. W., Clough, S. A., Payne, V. H., Smith, W. L., Kireev, S., and Cady-Pereira, K. E.: Performance of the line-by-line radiative transfer model (LBLRTM) for temperature and species retrievals: IASI case studies from JAIVEx, Atmos. Chem. Phys., 9, 7397-7417, doi:10.5194/acp-9-7397-2009, 2009.

Streets, D. G., Bond, T. C., Carmichael, G. R., Fernandes, S. D., Fu, Q., Klimont, Z., Nelson, S. M., Tsai, N. Y., Wang, M. Q., Woo, J.-H., and Yarber, K. F.: An inventory of gaseous and primary aerosol emissions in Asia in the year 2000, J. Geophys. Res, 108, 8809, doi:10.1029/2002JD003093, 2003.

Wang, Y., Jacob D. J., and Logan J. A.: Global simulation of tropospheric $\mathrm{O}_{3}-\mathrm{NO}_{\mathrm{x}}$ - hydrocarbon chemistry, 1. Model formulation, J. Geophys. Res., 103, 10713-10726, 1998.

Vestreng, V. and Klein, H.: Emission data reported to UNECE/EMEP: Quality insurance and trend analysis and presentation of Web-Dab, MSC-W Status Rep. 2002, 101 pp., Norw. Meteorol. Inst., Oslo, Norway.

Whitehead, J. D., Longley, I. D., and Gallagher, M. W.: Seasonal and Diurnal Variation in Atmospheric Ammonia in an Urban Environment Measured Using a Quantum Cascade Laser Absorption Spectrometer, Water Air Soil Pollut., 183, 317-329, doi:10.1007/s11270-007-9381-5, 2007.

Worden, J., Kulawik, S. S., Shephard, M. W., Clough, S. A., Worden, H., Bowman, K., and Goldman, A.: Predicted errors of tropospheric emission spectrometer nadir retrievals from spectral window selection, J. Geophys. Res., 109, D09308, doi:10.1029/2004JD004522, 2004.

Yevich, R. and Logan, J. A.: An assessment of biofuel use and burning of agricultural waste in the developing world, Global Biogeochem. Cy., 17, 1095, doi:10.1029/2002GB001952, 2003. 